\title{
Fecundity, Eggs, Larvae and Osteological Development of the Striped Searobin, (Prionotus evolans) (Pisces, Triglidae)
}

\author{
Paul Yuschak \\ Little Harbor Laboratory, Inc., \\ 69 Andrews Road, Guilford, Connecticut, USA 06437
}

\begin{abstract}
Fecundity of the striped searobin (Prionotus evolans) was estimated from the ovaries of 28 fish ( 3 to 5 years) to range from 90,000 to 218,000 eggs, with some indication of increase with length, weight and age. The preserved, fertilized eggs ranged in diameter from 0.21 to $0.57 \mathrm{~mm}$. Early development is described from eggs and larvae that were reared at temperatures of $19.0^{\circ}$ to $20.4^{\circ} \mathrm{C}$. The fertilized eggs ranged in diameter from 1.05 to $1.25 \mathrm{~mm}$ and contained 16-37 oil globules, which moved to various locations in the egg during development. Gastrulation occurred at $15 \mathrm{hr}$, early embryo at $25 \mathrm{hr}$ and first hatching at $80 \mathrm{hr}$. Characteristic pigment consists of a transverse band which is located about halfway between the vent and notochord tip in late-stage embryos and yolk-sac larvae. Newly-hatched larvae averaged $2.8 \mathrm{~mm} \mathrm{NL}$ and flexion occurred at $6.0-6.9 \mathrm{~mm}$. The pectoral fin is present at hatching and all fins are complete at $7.8 \mathrm{~mm} \mathrm{SL}$. Head spines are first evident at $6.2 \mathrm{~mm} \mathrm{NL}$, and they display prominent features during the course of development. Osteological development is nearly complete at $18.3 \mathrm{~mm} \mathrm{SL}$. Comparison of $P$ evolans with recently-published information on $P$. carolinus reveals differences in embryo pigmentation, head spine development, teeth formation and number of anal fin rays.
\end{abstract}

\section{Introduction}

The striped searobin (Prionotus evolans) is a common triglid of the western North Atlantic, occurring from South Carolina to Cape Cod and occasionally straying into the Gulf of Maine. In Long Island Sound, they appear in April and May when the water temperature rises above $6^{\circ} \mathrm{C}$ and leave in December when the temperature falls below $8^{\circ} \mathrm{C}$. Spawning takes place over sandy bottom in June and July when temperatures range from $13^{\circ}$ to $18^{\circ} \mathrm{C}$. Additional information on the biology and ecology of $P$. evolans can be found in papers by Nichols and Breeder (1927), Perlmutter (1939), Marshall (1946), Bigelow and Schroeder (1953), Wheatland (1956). Richards (1959), Liem and Scott (1966), McEachran and Davis (1970), Mann (MS 1974), Richards et al. (1979), and Roberts-Goodwin (1981).

Previous information on the early development of $P$. evolans is limited to a brief description of eggs which were thought to be those of $P$. evolans by Perlmutter (1939) and drawings of larvae in Fahay's (1983) guide to early stages of marine fishes. Reviews of the triglids by Ginsburg (1950) and Teague (1951) contain no information on the early life history of this species. No osteological data have been reported. In this paper, information is presented on the fecundity, early development and osteology of $P$. evolans, and comparisons are made with the northern searobin ( $P$. carolinus)

\section{Materials and Methods}

\section{Fecundity}

Twenty-eight striped searobins were collected in June 1983 from Long Island Sound in the vicinity of Little Harbor, Guilford, Connecticut. Each specimen was measured as standard length (SL) to the nearest millimeter and weighed to the nearest gram. Otoliths were removed for age determination. Whole otoliths were immersed in 95\% alcohol and examined for age under a binocular microscope on two occasions by two readers. The age readings did not agree for eight fish, and these are not included with the age-specific fecundity data. The ovaries were preserved in modified Gilson's fluid (Bagenal, 1967) and the jars were shaken vigorously at various times throughout preservation. The solution was changed after approximately 3 weeks, at which time the ovaries were teased apart with dissecting needles to aid in the separation of individual oocytes. After 3 months, the eggs were washed on a coarse screen to remove any remaining ovarian tissue.

The wet method, as described by Bagenal and Braum (1968), was used to obtain the oocyte counts. The eggs were placed in a beaker, diluted with water to a volume of $400 \mathrm{ml}$, and stirred to obtain a homogeneous distribution. Five $1-\mathrm{ml}$ subsamples of the mixture were taken and the eggs were counted under a binocular microscope. Fecundity was estimated by multiplying the mean number of eggs per milliliter by the total 
volume of the egg and water mixture from which the subsamples were taken. Oocyte measurements (diameters) were made with an ocular micrometer.

\section{Development}

Adult striped searobins were collected alive from trawl and gillnet catches in the central part of Long Island Sound during May and June 1984 and maintained in a flow-through seawater system at ambient temperature. Spawning was induced by hormone injection. At the onset of spawning, eggs and sperm were stripped from the fish into $21-\mathrm{cm}$ specimen dishes. After fertilization, the eggs were transferred to 75 and 1,500 liter tanks and kept suspended with gentle aeration. Temperatures ranged from $19.0^{\circ}$ to $20.4^{\circ} \mathrm{C}$. Light algae blooms were maintained in all rearing tanks throughout the experiment. First-feeding larvae were fed cultured rotifers and later stages fed on wild zooplankton, predominantly copepod nauplii and copepodites. One-quarter of the water in the rearing tanks was replaced each day.

Larvae were sampled at various stages of development and preserved in $3 \%$ buffered formalin for detailed study. Pigmentation of live larvae consists of melanophores, xanthophores and erythrophores, but the latter two types fade upon preservation. All three types of pigment are described in the text but only melanophores are represented in the illustrations. Morphological measurements follow Yuschak and Lund (1984).

Sixty-five larvae and 22 juveniles were differentially stained and cleared according to the method described by Potthoff (1984) for study of osteological development. All drawings of external features and bone development were produced with the aid of a camera lucida. Where applicable in the drawings, stippling denotes cartilage in order to distinguish it from bone.

\section{Fecundity}

The 28 ovaries from $P$. evolans were maturity stages 4 and 5 on the basis of the criteria of Schlossman and Chittenden (1981). The fish ranged in size from 21.0 to $26.2 \mathrm{~cm} \mathrm{SL}$ (mean 23.4, standard deviation 1.26) and in age from 2 to 5 years, with the majority being 3 years old. According to McEachran and Davis (1970) and Richards et al. (1979), P. evolans first spawn at age 2 and live for $7-9$ years.

Preserved, unfertilized oocytes within individuals ovaries ranged in diameter from 0.21 to $0.57 \mathrm{~mm}$ with a nean of $0.46 \mathrm{~mm}$ (standard deviation 0.10 ). The fecundity estimates ranged from 90,000 to 218,000 eggs ( $\Gamma$ able 1) and show a general increase with age. These
TABLE 1. Fecundity of $P$. evolans from Long Island Sound by agegroup. (SD = standard deviation.)

\begin{tabular}{lcrcr}
\hline \hline Age & $\begin{array}{c}\text { No. of } \\
\text { fish }\end{array}$ & \multicolumn{3}{c}{ Fecundity (number of eggs) } \\
\cline { 4 - 5 } (yr) & Mean & \multicolumn{1}{c}{ SD } & \multicolumn{1}{c}{ Range } \\
\hline 2 & 2 & 95,000 & 7,071 & $90,000-100,000$ \\
3 & 14 & 135,000 & 30,846 & $102,000-218,000$ \\
4 & 3 & 131,000 & 17,984 & $115,000-150,400$ \\
5 & 1 & 185,000 & - & - \\
\hline
\end{tabular}

estimates represent the total numbers of eggs in the ovaries and may not be indicative of the numbers of viable eggs that would be produced.

Great variability is evident in the plots of fecundity against length and somatic weight (body weight minus ovary weight) (Fig. 1), particularly for the rather narrow length and weight ranges which encompassed most of the specimens. A $21.6-\mathrm{cm}$ fish had an unusually high fecundity estimate (218,000 eggs), and this point was excluded from the calculations to determine the exponential relationships (Fig. 1), where $F$ is fecundity, $L$ is standard length and $W$ is weight. Contributing factors to these low regression coefficients in the searobin data are likely to be the small sample size and the scarcity of larger and older specimens.

\section{Egg Development}

The pelagic eggs of $P$. evolans are transparent with faint yellow coloration, and the chorion is lightly sculptured. Fertilized eggs ranged in diameter from 1.05 to $1.25 \mathrm{~mm}$ (mean, $\bar{x}=1.15$; standard deviation, $\mathrm{SD}=$ $0.094)$ and contained 16 to 37 oil globules $(\bar{x}=24, S D=$ 5.4 ) in a sample of $n=47$.

\section{Oil globule movement}

Oil globules in an unfertilized egg are scattered within one hemisphere (Fig. 2A). Upon fertilization and during early cell division, the globules are found to be concentrated in the area of the newly developing cells in some eggs and scattered within the hemisphere in others (Fig. 2B). At the multicell stage, the globules are arranged in a rough band at the egg equator (Fig. $2 \mathrm{C}$ and 2D). With the onset of epiplody, the oil globules migrate toward the site of blastopore closure, following which they disperse throughout the yolk periphery (Fig. $2 \mathrm{~F}$ to $2 \mathrm{H}$ ).

\section{Morphology}

Embryonic development in $P$. evolans is rapid, with the beginning of gastrulation occurring at $15 \mathrm{hr}$ and the embryonic shield being visible at $20 \mathrm{hr}$ (Fig. 2D and $2 \mathrm{E}$ ). The optic vesicles are visible when the embryo extends about one-quarter around the yolk (Fig. 2G), and they are well formed by the time the embryo 


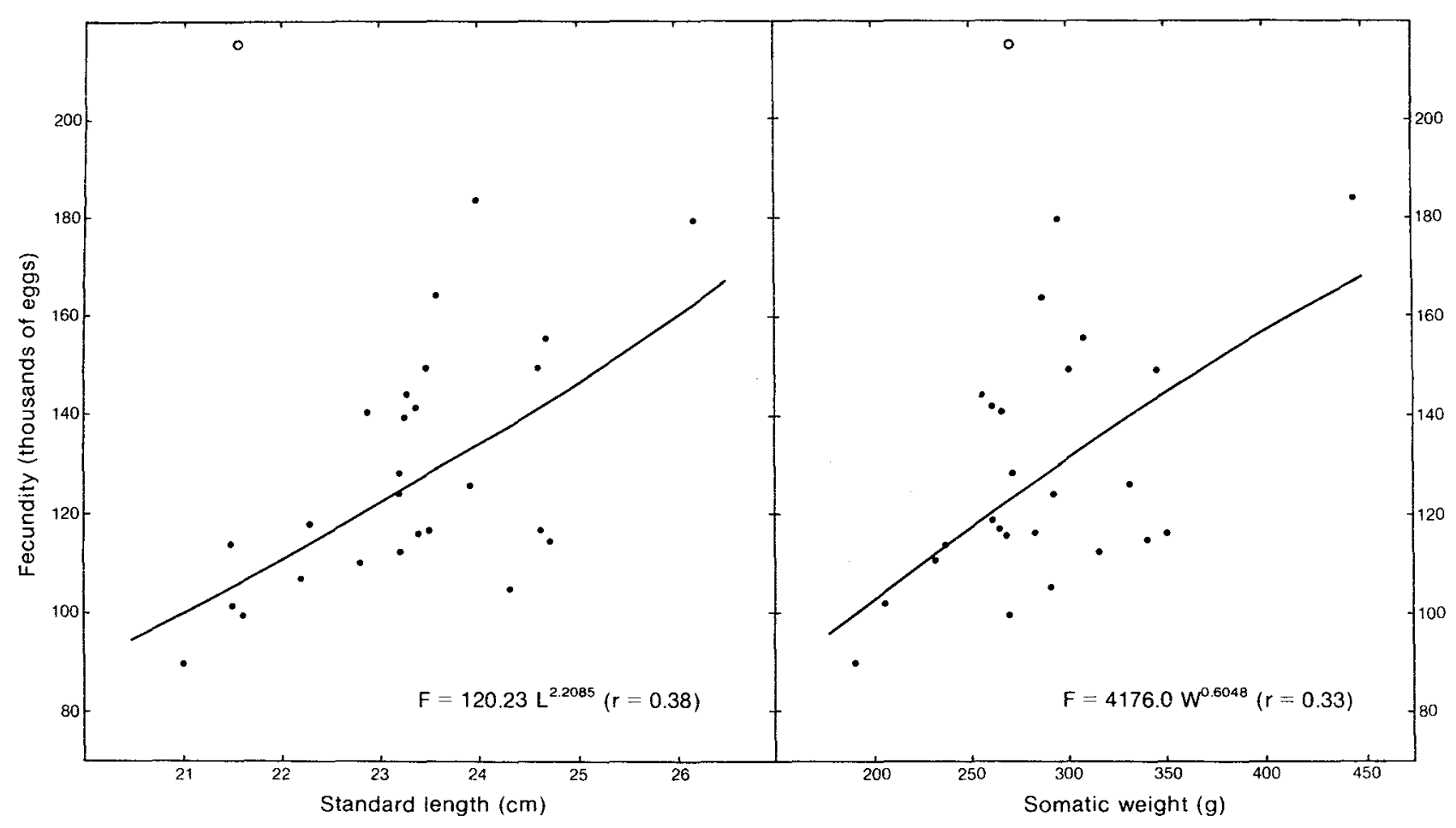

Fig. 1. Variation in fecundity of $P$. evolans with length and weight. (Data indicated by small circles were not included in calculating the equations.)

extends one-third around. Two somites and Kupffer's vesicle are also present (Fig. $2 \mathrm{H}$ ). When the embryo is halfway around the yolk, optic cups and the pericardial sac are present. Also, the brain begins to differentiate and the notochord has developed (Fig. 21). At this stage, 18-19 somites are present and a finfold starts to form in the caudal region. At five-eighths around the yolk, the heart is two-chambered and beating, and the first movements of the embryo are observed. Eye lenses are present and the tail deflects away from the embryonic axis. At this stage, 23 somites are visible (Fig. 2J).

When the embryo extends three-quarters around the yolk, the brain is well-differentiated, auditory vesicles are visible on either side of the brain, the lenses extrude past the optic margin, and the finfold has increased in width (Fig. $2 \mathrm{~K}$ ). Just prior to hatching, the tail slightly overlaps the head, the pectoral fin buds are elevated off the yolk surface, and 23-25 somites are visible (Fig. 2L). At this stage, the embryo is morphologically similar to the newly-hatched larva.

\section{Pigmentation}

Pigment is first visible when the embryo extends halfway around the yolk, with contracted melanophores and xanthophores scattered over the body and yolk surface (Fig. 21). When the embryo extends fiveeights around the yolk, both types of pigment have become stellate and have increased in density, and most of the melanophores are concentrated on the dorsal and dorsolateral surfaces of the head and body (Fig. 2J). At the stage when the embryo encircles threequarters of the yolk (Fig. 2K), the distribution of xanthophores is the same as in the previous stage. Melanophores are mostly stellate and are distributed on the dorsal and dorsolateral surfaces back to the vent. Posteriorly, they occur along the dorsal and ventral margins between the vent and halfway to the notochord tip. Here the concentration is denser, with one or two melanophores on the finfold and a few near the notochord tip. Just prior to hatching of the embryo (Fig. 2L), the melanophore pattern is similar to that in Fig. $2 \mathrm{~K}$, but the xanthophores, although less dense, are now concentrated on the finfold about halfway between the vent and notochord tip and along both the dorsal and ventral margins.

\section{Larval Development}

At incubation temperatures of $19^{\circ}$ to $20^{\circ} \mathrm{C}$, first hatching occurred at $80 \mathrm{hr}$ and was complete at $90 \mathrm{hr}$ after fertilization. The newly-hatched larvae averaged $2.8 \mathrm{~mm} \mathrm{NL}(\mathrm{SD}=1.77, \mathrm{n}=7)$. At this stage, a large yolk sac is present $(40 \% \mathrm{NL})$, the eyes are unpigmented, the mouth is undeveloped, and 14-20 oil globules are located mainly in the posterior half of the yolk sac (Fig. 3A). At $3.7 \mathrm{~mm} \mathrm{NL}$, the yolk sac is fully absorbed, a single loop is present in the digestive tract, the eyes and jaws are functional, and the larvae have commenced feeding (Fig. 3B). At $5.4 \mathrm{~mm} \mathrm{NL}$, the antero- 
A

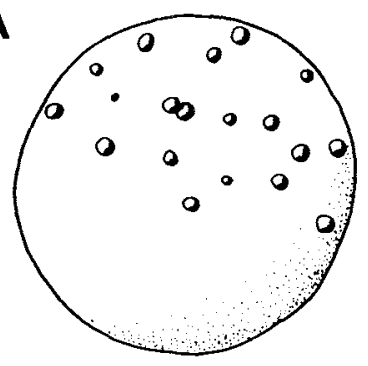

D

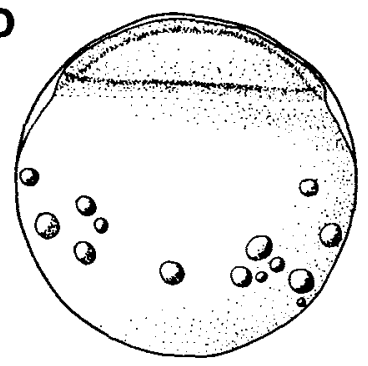

G
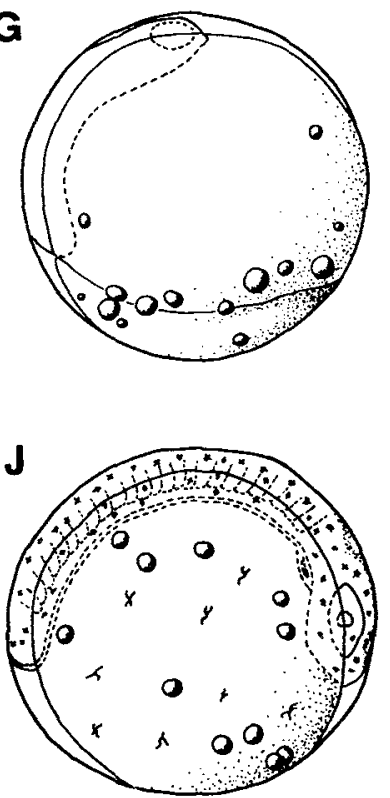

B

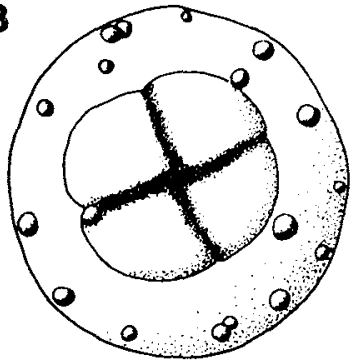

E

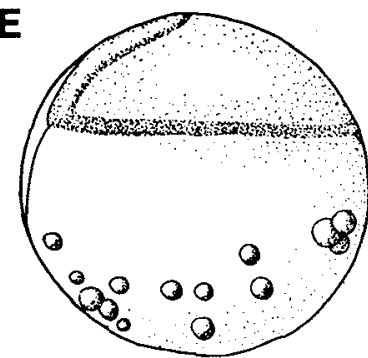

H

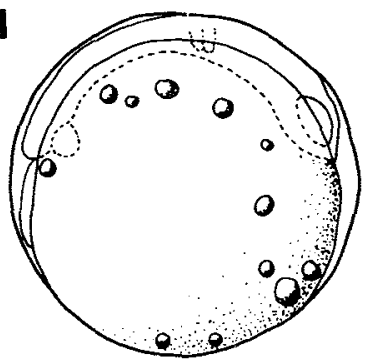

$\mathbf{K}$

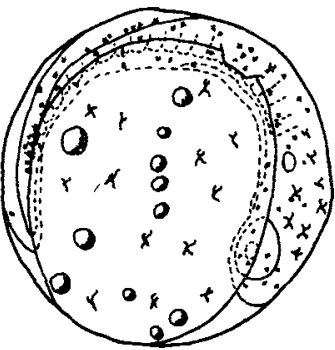

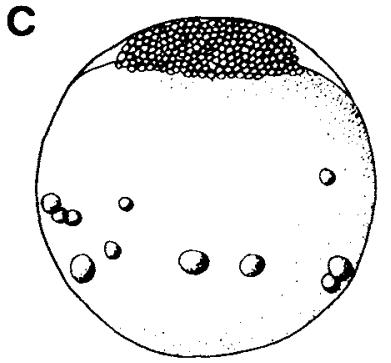

$\mathbf{F}$

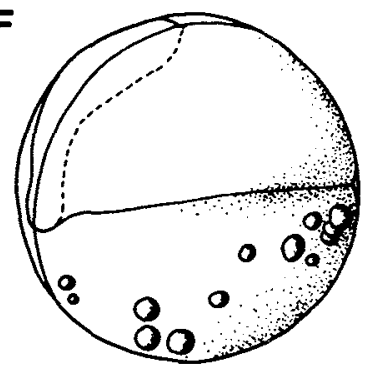

I

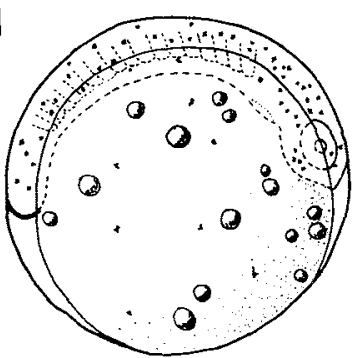

$\mathbf{L}$

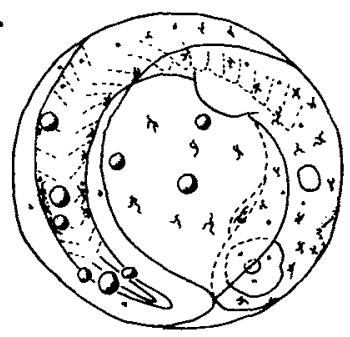

$1.0 \mathrm{~mm}$

Fig. 2. Developmental stages of $P$. evolans eggs: A, unfertilized egg; B, four-cell $(0.5 \mathrm{hr}) ; \mathbf{C}$, multicell ( $6 \mathrm{hr})$; D. gastrula (15 hr); E, gastrula (20 hr); F, early embryo (25 hr); G. embryo one-quarter around yolk (28 $\mathrm{hr}$ ); $\mathbf{H}$, embryo one-third around yolk ( $31 \mathrm{hr}) ; \mathbf{l}$, embryo half around yolk ( $39 \mathrm{hr}$ ); J, embryo fiveeights around yolk ( $48 \mathrm{hr}) ; \mathrm{K}$, embryo three-quarters around yolk $(62 \mathrm{hr}) ; \mathrm{L}$, embryo fully around yolk $(77 \mathrm{hr})$.

dorsal part of the head begins to flatten, and this continues until the characteristic adult shape is attained (Fig. 3D). A single row of teeth is present on the upper jaw at $5.8 \mathrm{~mm} \mathrm{NL}$ and on the lower jaw at 6.6 $\mathrm{mm} \mathrm{SL} \mathrm{(Fig.} \mathrm{3E} \mathrm{and} 3 \mathrm{~F}$ ). The adult complement of fin rays and spines is present at $8.6 \mathrm{~mm} \mathrm{SL}$ (Fig. $3 \mathrm{H}$ ).

\section{Pigmentation}

Pigment of the yolk-sac larvae consists of lightly scattered melanophores and xanthophores on the head, trunk and yolk-sac surface (Fig. 3A). A transverse band is present approximately halfway between 

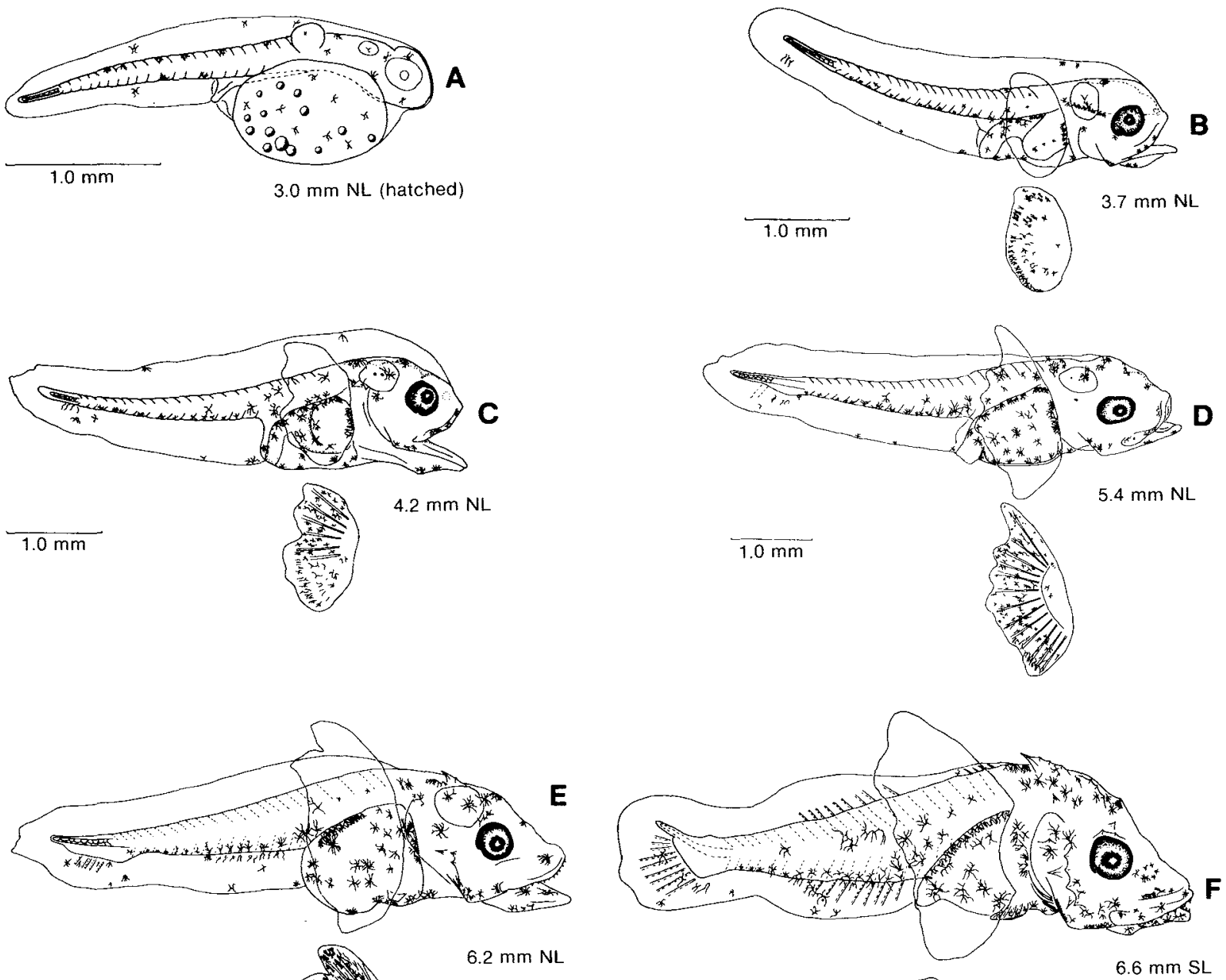

$100 \mathrm{~mm}$

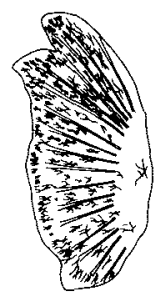

$6.2 \mathrm{~mm} \mathrm{NL}$
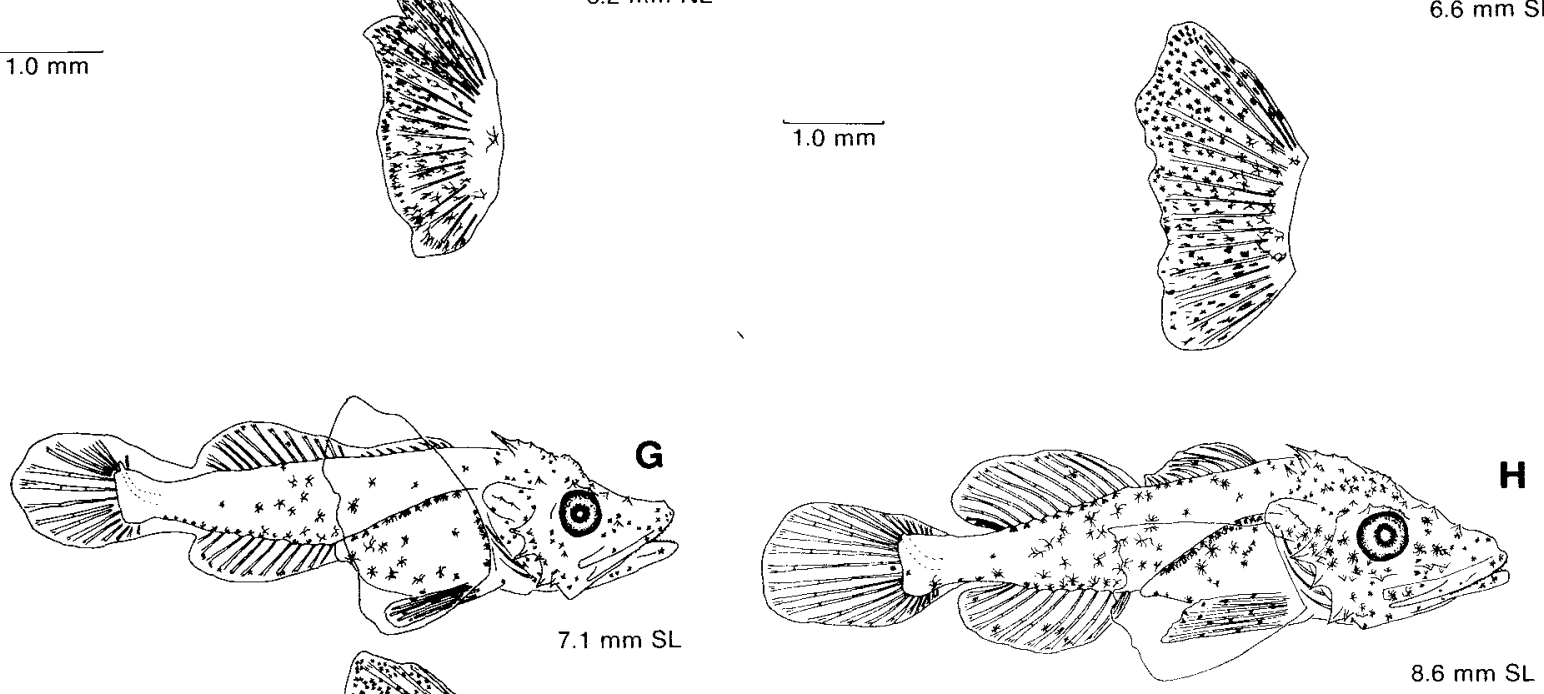

$\overline{1.0 \mathrm{~mm}}$
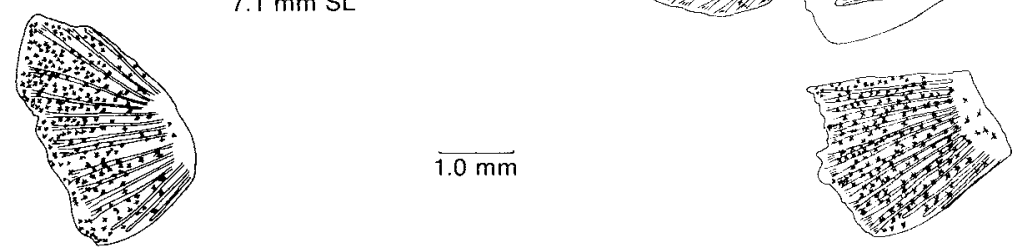

Fig. 3. Developmental stages of $P$. evolans from hatching at $3.0 \mathrm{~mm} \mathrm{NL}$ to early juvenile at $8.6 \mathrm{~mm} \mathrm{SL}$. 
the vent and notochord tip. Both melanophores and xanthophores are present along the dorsal and ventral margins from the vent posteriorly to just beyond the transverse band. Xanthophores are present along the posterior margin of the vent and on the dorsal surface of the pectoral fins. Additional pigmentation on the finfold consists of one or two melanophores and several xanthophores above the pectoral fin.

At $3.7 \mathrm{~mm} \mathrm{NL} \mathrm{(Fig.} \mathrm{3B),} \mathrm{yellow} \mathrm{pigmentation} \mathrm{is}$ greatly reduced, with a few xanthophores remaining on the gut surface. The transverse band and the row of pigment along the dorsal margin is absent, but melanophores are present on the dorsal, lateral and anterior surfaces of the gut. Pigment in the vicinity of the brain consists of a single melanophore over the mid-brain and a row under the hind-brain. A row of pigment is visible along the margin of the upper jaw and along the midline of the lower jaw, with a few single melanophores scattered on the lateral surfaces of the head and jaw complex. Finfold pigment consists of single melanophores above the otic capsule and along the ventral margin, with two or three at the site of caudal fin formation. Melanophores on the pectoral fins continue to increase in density with development.

At $4.2 \mathrm{~mm} \mathrm{NL}$ (Fig. 3C), the gut and trunk are more heavily pigmented than before and melanophores are scattered over both the mid-brain and hind-brain. Pigment extends along the ventral margin to the notochord tip. Finfold pigment is similar to that in the earlier stage

At $5.4 \mathrm{~mm} \mathrm{NL}$ (Fig. 3D), pigment intensifies on the gut surface and on the pectoral fins, but pigment on the head, trunk and finfold remains similar to that of 4.2 $\mathrm{mm}$ larvae. At $6.2 \mathrm{~mm} \mathrm{NL}$ (Fig. 3E), pigment starts to intensify on the head and mid-trunk region. The row of stellate melanophores along the ventral margin now extends onto the finfold at the site of anal fin formation. At this stage, erythrophores are present along the lateral midline of the trunk.

In 6.6-8.6 $\mathrm{mm} \mathrm{SL} \mathrm{larvae} \mathrm{(Fig.} 3 \mathrm{~F}$ to $3 \mathrm{H}$ ), there is a general increase in pigment on the head, body and paired fins but not on the median fins which are lightly pigmented. A prominent feature is the lack of pigment on the caudal peduncle of all specimens that were examined.

\section{Fin development}

The finfold, which is the prominent fin structure of a!i larvae smaller than $5.2 \mathrm{~mm} \mathrm{NL}$, diminishes as the median fins develop and is absent at $8.6 \mathrm{~mm} \mathrm{SL}$. The sequence of fin development is pectoral, anal, pelvic, caudal, second dorsal and first dorsal (Table 2).
TABLE 2. Development of fins in reared larvae of $P$. evolans

\begin{tabular}{lcccc} 
& $\begin{array}{c}\text { Buds } \\
\text { first } \\
\text { appear }\end{array}$ & $\begin{array}{c}\text { First } \\
\text { appear }\end{array}$ & $\begin{array}{c}\text { Full } \\
\text { complement }\end{array}$ & $\begin{array}{c}\text { Number in fully } \\
\text { developed fins }\end{array}$ \\
\hline Pectoral & 2.9 & $4.0 \mathrm{NL}$ & $5.8 \mathrm{NL}$ & $\begin{array}{l}12-13 \text { (rarely 14) } \\
\text { and 3 feeler rays }\end{array}$ \\
Pelvic & 6.2 & $6.5 \mathrm{SL}$ & $7.5 \mathrm{SL}$ & 1,5 \\
Caudal (principal) & - & $5.8 \mathrm{NL}$ & $7.5 \mathrm{SL}$ & 13 \\
Anal & - & $6.4 \mathrm{SL}$ & $7.1 \mathrm{SL}$ & 11 (rarely 10,12) \\
First dorsal & - & $6.5 \mathrm{SL}$ & $7.8 \mathrm{SL}$ & $\times$ (rarely IX) \\
Second dorsal & - & $6.5 \mathrm{SL}$ & $7.7 \mathrm{SL}$ & 12 (rarely 11,13) \\
\hline
\end{tabular}

The pectoral fin is evident at hatching and six rays are visible at $4.2 \mathrm{~mm} \mathrm{NL}$ (Fig. 3C). The full complement of rays is attained at $5.8 \mathrm{~mm} \mathrm{NL}$, with the three feeler rays becoming separate at $11.5 \mathrm{~mm} \mathrm{SL}$. The pelvic fin is present as a bud at $6.2 \mathrm{~mm} \mathrm{NL}$ (Fig. 3E), a spine and two rays are visible at $6.5 \mathrm{~mm} \mathrm{SL}$, and the full complement of rays is evident at $7.5 \mathrm{~mm} \mathrm{SL}$

The principal caudal fin rays are first evident at 5.8 $\mathrm{mm} \mathrm{NL}$, and the adult number (13) is present at $7.5 \mathrm{~mm}$ $\mathrm{SL}$. Eight anal fin rays are present at $6.4 \mathrm{~mm} \mathrm{SL}$, and the adult number is attained at $7.1 \mathrm{~mm} \mathrm{SL}$. The first and second dorsal fins have four spines and nine rays respectively at $6.5 \mathrm{~mm} \mathrm{SL}$, and the full complements of both are present at 7.8 and $7.7 \mathrm{~mm} \mathrm{SL}$ respectively.

\section{Head spine development}

The general pattern of head spine development in $P$. evolans is similar to that in $P$. carolinus (Yuschak and Lund, 1984), with an increase in number and size of spines during early development and a subsequent decrease to those present in adults. Only the early stages of spine development are described here. Spine terminology was adapted from Teague (1951) and Miller $(1965,1967)$.

At $6.2 \mathrm{~mm} \mathrm{NL}$ (Fig. 3E), the nuchal spine is present dorsal to the otic capsule, and four preopercle spines are evident. The nuchal spine continues to grow in size throughout development. Visible at $6.6 \mathrm{~mm} \mathrm{SL} \mathrm{(Fig.} \mathrm{3F)}$ are an opercle spine, a sphenotic spine, three postocular spines and a parietal ridge with three spines. At 7.6 $\mathrm{mm} \mathrm{SL} \mathrm{(Fig.} \mathrm{3G),} \mathrm{there} \mathrm{is} \mathrm{an} \mathrm{increase} \mathrm{in} \mathrm{spination,} \mathrm{with}$ spines present in the posttemporal, preorbital, preocular, suborbital and nasal areas. The numbers of opercle and preopercle spines has increased to two and six respectively. In the $8.6 \mathrm{~mm} \mathrm{SL}$ specimen (Fig. $3 \mathrm{H}$ ), no new spines are evident, and all spines that were present at earlier stages had increased in size with some forming prominent ridges. Additional information on spine development that is associated with the opercle and 
pectoral complexes is presented in the section on osteology.

\section{Morphometrics}

Morphometric data for reared $P$. evolans larvae are summarized in Table 3 . The proportion of head length to body length increased from $24.8 \%$ at hatching to $25.8-29.9 \%$ during flexion and to $40.2-44.8 \%$ in $10-\mathrm{mm}$ and larger specimens. The proportion of body depth to body length increased from $18.6 \%$ at yolk-sac absorption to $24.2-28.4 \%$ at flexion and to $31.6-42.5 \%$ in $9-\mathrm{mm}$ and larger specimens. The proportion of eye diameter to body length remained relatively constant during preflexion (6.6-11.5\%), flexion (6.5-7.5\%) and postflexion $(6.9-11.9 \%)$. The proportions of snout-anus length to body length were $46.7-53.7 \%$ during preflexion, 51.6-55.2\% during flexion and 55.6-68.6\% during postflexion.

\section{Osteology}

Osteological terminology in this section follows that of Gosline (1961), Potthoff (1974, 1975), Houde and Potthoff (1976), Peters (1981), and Yuschak and Lund (1984).

\section{Jaws (Fig. 4, Appendix Table A)}

At hatching ( $2.8 \mathrm{~mm} \mathrm{NL})$, the jaw consists of Meckel's cartilage, the quadrate which joins Meckel's cartilage at its ventral tip, and the hyomandibular which is separate from the other structures (Fig. 4A). At $3.1 \mathrm{~mm}$ $\mathrm{NL}$, the hyomandibular joins the pterotic region of the skull and extends ventrally to join the quadrate along its anteroventral surface. The major condyles are beginning to form at this size. Ossification of the hyomandibular begins at $7.4 \mathrm{~mm} \mathrm{SL}$ and is complete at $15.2 \mathrm{~mm}$ SL.

The quadrate is present as a thin sheet of cartilage which articulates with Meckel's cartilage and joins the hyomandibular at $3.1 \mathrm{~mm} \mathrm{NL}$ (Fig. 4A). Dorsal and ventral expansion begins at $5.0 \mathrm{~mm} \mathrm{NL}$, forming the palato-quadrate complex which connects to the ethmoid region of the skull at $6.3 \mathrm{~mm} \mathrm{NL}$. The palatoquadrate begins to differentiate into the jaw suspensorium at $11.5 \mathrm{~mm} \mathrm{SL}$, with the formation of the symplectic, and is complete at $17.1 \mathrm{~mm}$ SL. Ossification of the jaw suspensorium is first evident in the quadrate at $11.5 \mathrm{~mm} \mathrm{SL}$ and is complete at $31.0 \mathrm{~mm} \mathrm{SL}$ (Fig. 4E). At this size, the quadrate is joined to the hyomandibular by the symplectic and the metapterygoid, which articulates with the hyomandibular at a mid-anterior condyle. The entopterygoid and ectopterygoid join the quadrate and metapterygoid to the palatine, which articulates with the maxillary. The
TABLE 3. Morphometric data for reared larvae of $P$. evolans by size group. $(\mathrm{BL}=$ body length, $\mathrm{BD}=$ body depth, $\mathrm{HL}=$ head length,$E D=$ eye diameter, $S A=$ snout to anus length. Data in bold refer to specimens undergoing notochord flexion.)

\begin{tabular}{|c|c|c|c|c|c|c|}
\hline \multirow{2}{*}{$\begin{array}{c}\text { Size } \\
\text { group } \\
(\mathrm{mm})\end{array}$} & \multirow{2}{*}{$\begin{array}{c}\text { Sample } \\
\text { size }\end{array}$} & \multirow{2}{*}{$\begin{array}{c}\text { Mean } \\
\text { length } \\
(\mathrm{mm})\end{array}$} & \multicolumn{4}{|c|}{ Ratios of mean measurements $(\%)$} \\
\hline & & & $\mathrm{HL} / \mathrm{BL}$ & $\mathrm{BD} / \mathrm{BL}$ & $E D / B L$ & $\mathrm{SA} / \mathrm{BL}$ \\
\hline $2.5-2.9$ & 7 & 2.6 & $一$ & - & 11.5 & 53.8 \\
\hline $3.0-3.4$ & 8 & 3.2 & 24.8 & 18.6 & 9.4 & 46.9 \\
\hline $3.5-3.9$ & 6 & 3.7 & 24.3 & 21.6 & 8.1 & 45.9 \\
\hline $4.0-4.4$ & 4 & 4.2 & 26.2 & 21.4 & 7.1 & 50.0 \\
\hline $4.5-4.9$ & 1 & 4.5 & 26.7 & 33.3 & 6.6 & 46.7 \\
\hline $5.0-5.4$ & 3 & 5.1 & 27.5 & 23.5 & 7.8 & 50.9 \\
\hline $5.5-5.9$ & 6 & 5.6 & 27.3 & 24.0 & 6.7 & 51.3 \\
\hline $6.0-6.4$ & 9 & 6.2 & 25.8 & 24.2 & 6.5 & 51.6 \\
\hline $6.5-6.9$ & 9 & 6.7 & 29.9 & 28.4 & 7.5 & 55.2 \\
\hline $7.0-7.4$ & 6 & 7.2 & 30.6 & 29.2 & 6.9 & 55.6 \\
\hline $7.5-7.9$ & 5 & 7.7 & 33.8 & 28.6 & 7.7 & 58.4 \\
\hline $8.0-8.4$ & 8 & 8.1 & 33.3 & 28.4 & 8.6 & 59.3 \\
\hline $8.5-8.9$ & 8 & 8.6 & 34.9 & 29.1 & 8.1 & 61.6 \\
\hline $9.0-9.4$ & 16 & 9.1 & 39.6 & 34.1 & 8.8 & 62.6 \\
\hline $9.5-9.9$ & 8 & 9.7 & 39.2 & 34.0 & 10.3 & 62.9 \\
\hline $10.0-10.4$ & 15 & 10.1 & 40.6 & 33.7 & 9.9 & 62.4 \\
\hline $10.5-10.9$ & 5 & 10.7 & 40.2 & 35.2 & 9.3 & 62.6 \\
\hline $11.0-11.4$ & 6 & 11.3 & 40.7 & 42.5 & 9.7 & 62.8 \\
\hline $11.5-11.9$ & 1 & 11.7 & 44.4 & 35.0 & 11.9 & 64.1 \\
\hline $12.0-12.4$ & 3 & 12.2 & 42.6 & 36.1 & 9.8 & 64.8 \\
\hline $13.0-13.4$ & 3 & 13.1 & 42.7 & 34.4 & 10.6 & 65.6 \\
\hline $13.5-13.9$ & 2 & 13.7 & 40.1 & 35.8 & 10.2 & 68.6 \\
\hline $14.0-14.4$ & 1 & 14.1 & 43.3 & 31.9 & 11.3 & 63.8 \\
\hline $15.0-15.4$ & 3 & 15.1 & 40.4 & 35.1 & 10.6 & 64.2 \\
\hline $15.5-15.9$ & 2 & 15.5 & 43.9 & 31.6 & 11.6 & 66.6 \\
\hline $16.5-16.9$ & 1 & 16.5 & 44.8 & 36.8 & 10.9 & 67.3 \\
\hline $17.0-17.4$ & 1 & 17.0 & 44.1 & 35.3 & 8.8 & 65.3 \\
\hline $18.5-18.9$ & 1 & 18.8 & 42.6 & 34.6 & 11.2 & 61.7 \\
\hline $19.0-19.4$ & 1 & 19.0 & 44.7 & 32.6 & 10.0 & 68.4 \\
\hline
\end{tabular}

development of teeth on the palatine and vomer was not noted, but their formation was complete at $31.0 \mathrm{~mm}$ SL (Fig. 4E).

The articular and dentary cartilages begin to differentiate at $4.0 \mathrm{~mm} \mathrm{NL} \mathrm{(Fig.} \mathrm{4B)} \mathrm{and} \mathrm{are} \mathrm{separate}$ structures at $7.1 \mathrm{~mm}$ SL. Short conical teeth are first present in a single row at $6.5 \mathrm{~mm} \mathrm{SL}$ and become more numerous at $8.3 \mathrm{~mm} \mathrm{SL}$ (Fig. 4D). They are reduced to bands of cardiform teeth at $31.0 \mathrm{~mm} \mathrm{SL}$ (Fig. 4E).

The upper jaw is first represented by the maxilla which appears at $3.1 \mathrm{~mm} \mathrm{NL}$ as a thin bar of cartilage (Fig. 4B). The premaxilla is present anterior to the maxilla at $5.0 \mathrm{~mm} \mathrm{NL}$ (Fig. 4C), and these structures articulate with each other at their dorsal tips at $5.2 \mathrm{~mm}$ NL. Teeth appear on the premaxilla at $5.8 \mathrm{~mm} \mathrm{NL}$ as short conical structures in a single row. They increase in number and become recurved as the larva grows (Fig. 4D). Regeneration to bands of cardiform teeth begins at approximately $11.0 \mathrm{~mm} \mathrm{SL}$ and is complete at $31.0 \mathrm{~mm}$ SL (Fig. 4E). Ossification of the upper jaw commences at the dorsal tips at $5.0 \mathrm{~mm} \mathrm{NL}$ (Fig. $4 \mathrm{C}$ ) and progresses posteriorly until completion at $7.1 \mathrm{~mm}$ SL. 
A
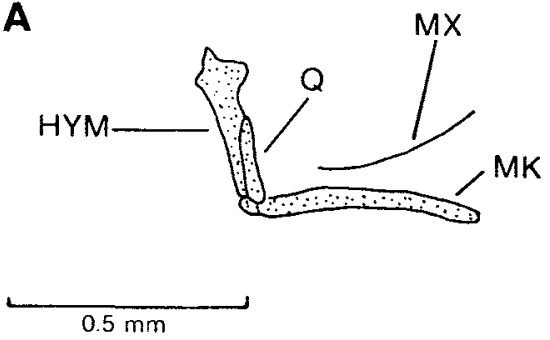

C

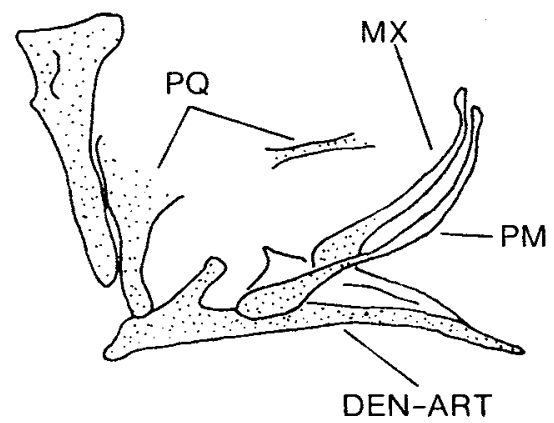

$0.5 \mathrm{~mm}$

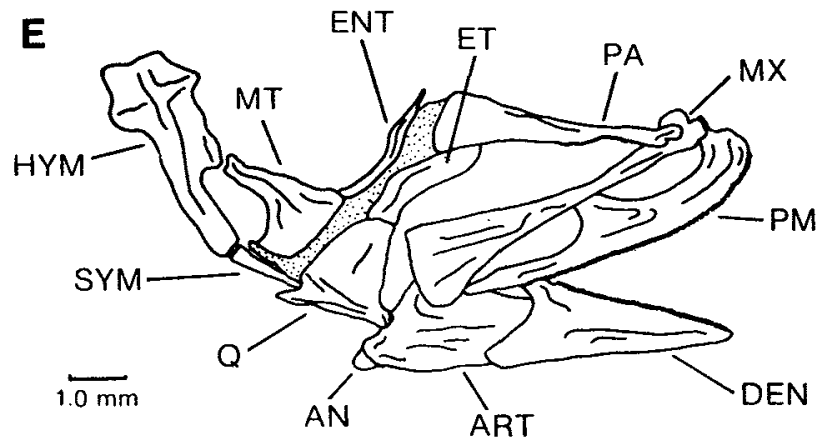

B
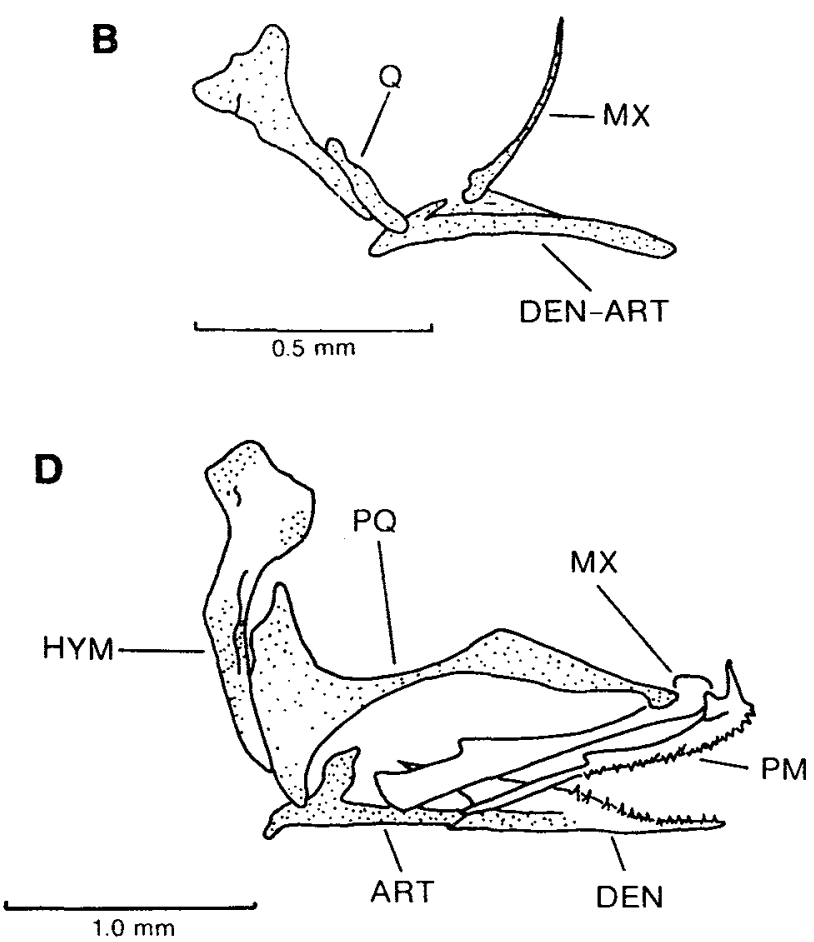

Fig. 4. Right lateral view of jaw and suspensorium development in P. evolans: A, $3.1 \mathrm{~mm} \mathrm{NL} ; \mathbf{B}, 4.0 \mathrm{~mm} \mathrm{NL}: \mathbf{C}, 5.0 \mathrm{~mm} \mathrm{NL} ; \mathbf{D}, 8.3 \mathrm{~mm} \mathrm{SL}: \mathbf{E}, 31.0 \mathrm{~mm}$ SL.

\section{Branchial arch (Fig. 5, Appendix Table B)}

The branchial arch in the $3.1 \mathrm{~mm}$ NL specimen (Fig. 5A) consists of basibranchials 1-3, ceratobranchials 1-4 and hypobranchials 1-3. Connection of the ceratobranchials and hypobranchials begins at $5.2 \mathrm{~mm}$ $\mathrm{NL}$, at which time epibranchials $1-4$ and the upper and lower pharyngeals are present (Fig. 5B). At $6.1 \mathrm{~mm} \mathrm{NL}$, 4-6 teeth are present on both the upper and lower pharyngeals, and the ceratobranchials have curved upward to join the epibranchials. At $8.3 \mathrm{~mm} \mathrm{SL}$, the teeth are sharply conical and their number has increased to 9-13 (Fig. 5D). As the teeth continue to increase in number, they become reduced to bands of cardiform teeth at $31.0 \mathrm{~mm} \mathrm{SL}$. Ossification begins in the ceratobranchials at $7.5 \mathrm{~mm} \mathrm{SL}$ and in the remaining structures at $9.0 \mathrm{~mm} \mathrm{SL}$. It is almost complete at 31.0 $\mathrm{mm} \mathrm{SL}$, with only the anterior tips of the hypobranchials remaining as cartilage (Fig. 5E).

\section{Hyoid arch (Fig. 6, Appendix Table C)}

The hyoid arch is visible as a bar of cartilage in the $3.1 \mathrm{~mm} \mathrm{NL}$ larva (Fig. 6A). Separation into the epihyal and ceratohyal occurs at $15.2 \mathrm{~mm} \mathrm{SL}$, and the adult form is present at $31.0 \mathrm{~mm} \mathrm{SL}$ (Fig. 6E).

The interhyal is present at hatching and the basihyal appears at $3.8 \mathrm{~mm} \mathrm{NL}$. Ossification of both structures is not quite complete in the $31.0 \mathrm{~mm}$ specimen (Fig. 6E). The urohyal and glossohyal are visible at 6.2 and $6.4 \mathrm{~mm} \mathrm{SL}$ respectively. The urohyal is completely ossified at $7.8 \mathrm{~mm} \mathrm{SL}$, but the posterior tip of the glossohyal is cartilaginous at $31.0 \mathrm{~mm} \mathrm{SL}$. Three branch- 
A

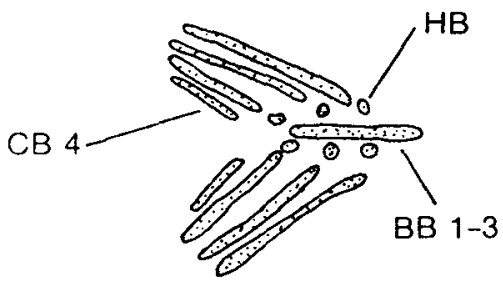

$0.5 \mathrm{~mm}$

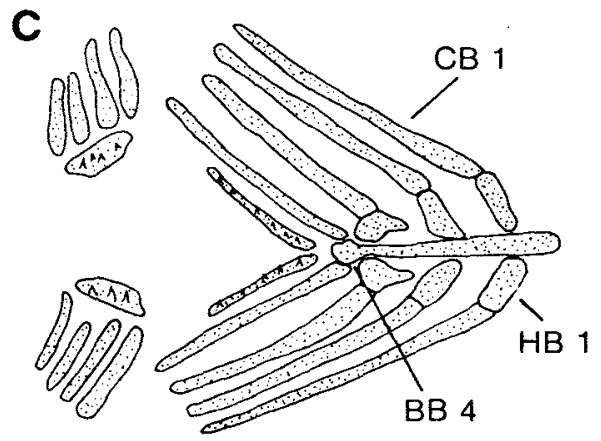

B

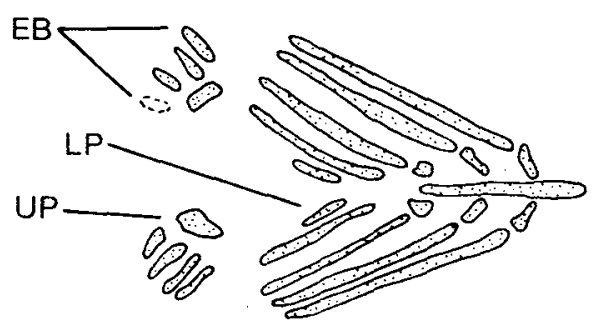

$0.5 \mathrm{~mm}$

D

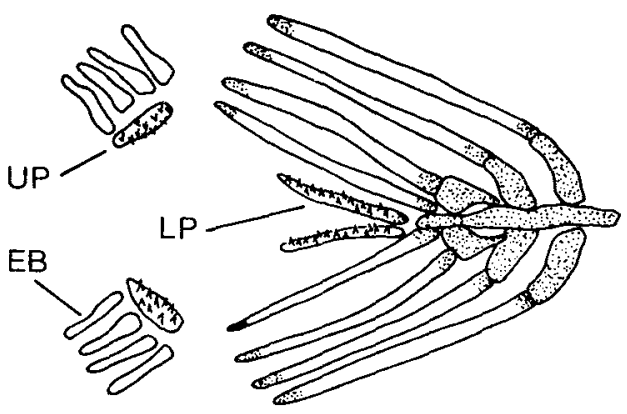

$0.5 \mathrm{~mm}$

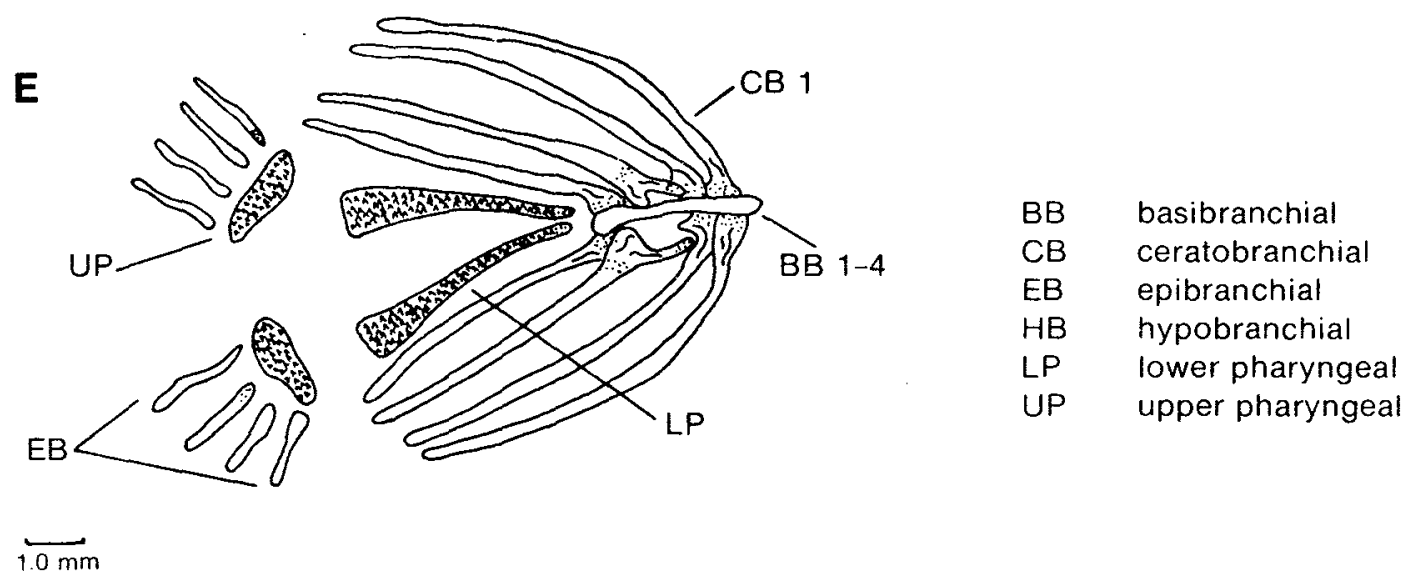

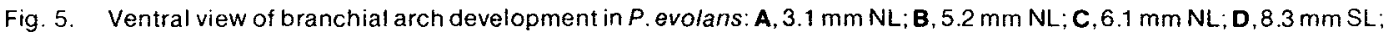
E, $31.0 \mathrm{~mm} \mathrm{SL}$.

iostegal rays are visible at $5.0 \mathrm{~mm} \mathrm{NL}$ and the adult complement (7) is present at $6.1 \mathrm{~mm} \mathrm{NL}$ (Fig. 6C). Ossification of the rays begins with the posterior-most ray at $7.5 \mathrm{~mm} \mathrm{SL}$ and proceeds anteriorly.

\section{Opercle complex (Fig. 7, Appendix Table D)}

Opercle cartilage is absent until the larvae reach $5.2 \mathrm{~mm} \mathrm{NL}$ (Fig. 7A). At this size, the opercle and preopercle are visible posterior to the hyomandibular.
The opercle articulates with the hyomandibular and begins to expand at $5.7 \mathrm{~mm} \mathrm{NL}$ (Fig. 7B). A 'ridge forms on the opercle at $6.1 \mathrm{~mm} \mathrm{NL}$ and a single spine is present at $7.1 \mathrm{~mm} \mathrm{SL}$ (Fig. 7D). Three large spines are present on the opercle at $8.3 \mathrm{~mm} \mathrm{SL}$ (Fig. $7 \mathrm{E}$ ), but these degenerate to a row of low spines at $31.0 \mathrm{~mm} \mathrm{SL}$ (Fig. $7 F$ ).

The preopercle has three spines at $5.7 \mathrm{~mm} \mathrm{NL}$ (Fig. $7 \mathrm{~B})$, and the large spine that is characteristic of adults 
A

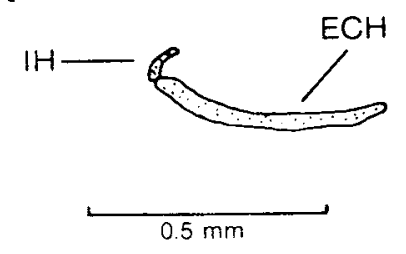

C

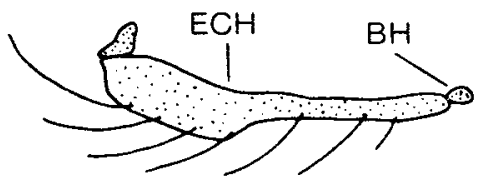

$0.5 \mathrm{~mm}$
B
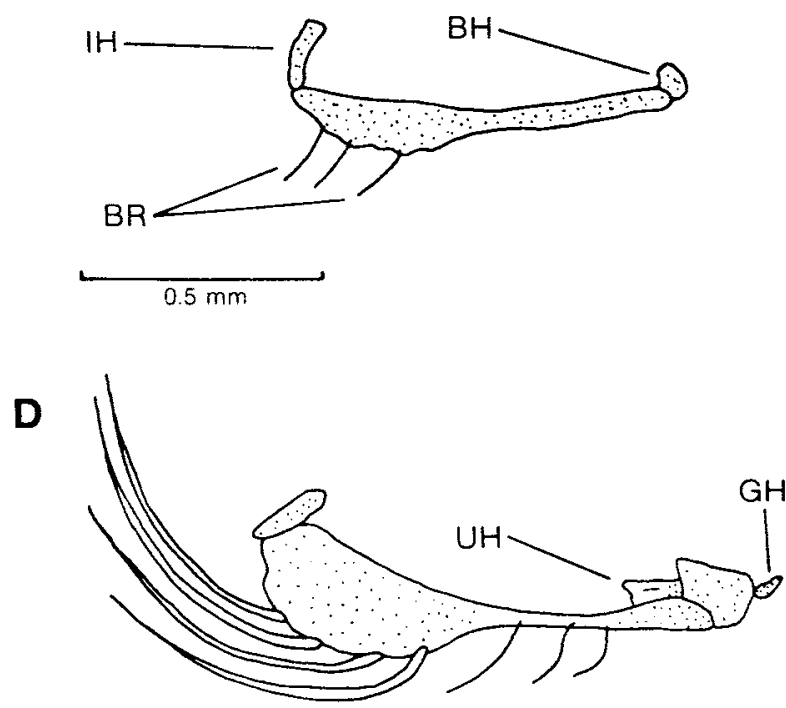

$0.5 \mathrm{~mm}$

E

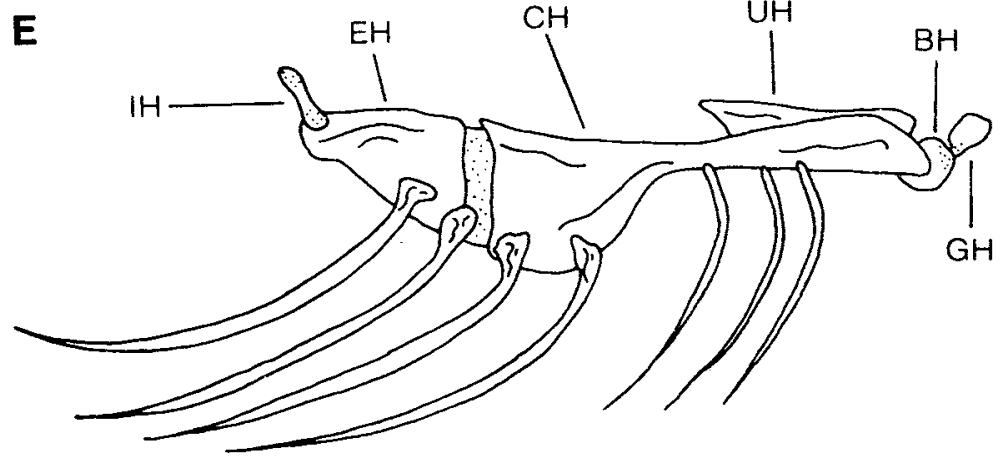

basihyal

BR branchiostegal ray

$\mathrm{CH}$ ceratohyal

$\mathrm{ECH}$ epiceratohyal

$\mathrm{EH}$ epihyal

$\mathrm{GH}$ glossohyal

IH interhyal

UH urohyal

$\overline{1.0 \mathrm{~mm}}$

Fig. 6. Right lateral view of hyoid arch development in P. evolans: A, $3.1 \mathrm{~mm} \mathrm{NL;} \mathrm{B,} 5.2 \mathrm{~mm} \mathrm{NL;} \mathrm{C,} 6.1 \mathrm{~mm} \mathrm{NL.;} \mathrm{D,} 8.3 \mathrm{~mm} \mathrm{SL;} \mathrm{E,}$ $31.0 \mathrm{~mm} \mathrm{SL}$

begins to form at $6.1 \mathrm{~mm} \mathrm{NL}$ (Fig. 7C). At $7.1 \mathrm{~mm} \mathrm{SL}$, two lateral spines, two posterior spines and two posteroventral spines are present (Fig. 7D). The preopercle continues to increase in size and six large spines are visible at $8.3 \mathrm{~mm} \mathrm{SL} \mathrm{(Fig.} \mathrm{7E).} \mathrm{These} \mathrm{prominent} \mathrm{spines}$ subsequently decline in number, and only two are present at $31.0 \mathrm{~mm} \mathrm{SL} \mathrm{(Fig.} \mathrm{7F).}$

The interopercle and subopercle appear at $6.4 \mathrm{~mm}$ $\mathrm{SL}$ and $6.5 \mathrm{~mm} \mathrm{SL}$ respectively as thin sheets of cartilage posterior to the opercle and preopercle. At $7.1 \mathrm{~mm}$ $\mathrm{SL}$, both the opercle and preopercle have expanded over the two structures (Fig. 7D). The interopercle and subopercle remain beneath the opercle and preopercle in juveniles (Fig. 7F) and in adults.

Ossification of the opercle complex begins at 6.0 $\mathrm{mm} \mathrm{NL}$ in the posterior part of the opercle. The pre- opercle begins to ossify at $6.3 \mathrm{~mm} \mathrm{SL}$, and both are bones at $6.9 \mathrm{~mm} \mathrm{SL}$. The interopercle and subopercle do not become fully ossified until 8.3 and $8.0 \mathrm{~mm} \mathrm{SL}$ respectively.

\section{Pectoral fins (Fig. 8, Appendix Table E)}

The cleithrum, which is present as a thin line of cartilage at hatching, expands dorsally and ventrally and is readily seen in the $3.1 \mathrm{~mm} \mathrm{NL}$ larva (Fig. 8A). Expansion of the cleithrum continues (Fig. 8B), and articulation of its dorsal tip with the supracleithrum is visible at $5.8 \mathrm{~mm} \mathrm{NL}$ (Fig. $8 \mathrm{C}$ ). A dorsal postcleithrum structure forms under the developing rays at $8.3 \mathrm{~mm} \mathrm{SL}$ (Fig. 8E) and becomes fully ossified shortly thereafter. Ossification of the cleithrum begins at $6.0 \mathrm{~mm} \mathrm{NL}$ and is complete at $6.5 \mathrm{~mm} \mathrm{SL}$. The adult structure of the pectoral girdle with the prominent cleithral spine is represented in the $31.0 \mathrm{~mm} \mathrm{SL}$ specimen (Fig. 8F). 
A

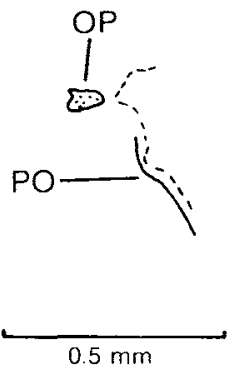

B

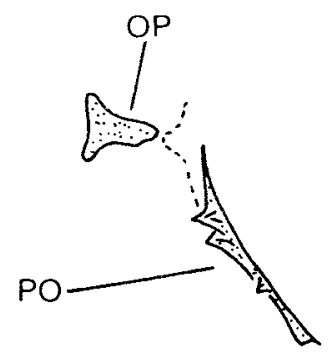

C

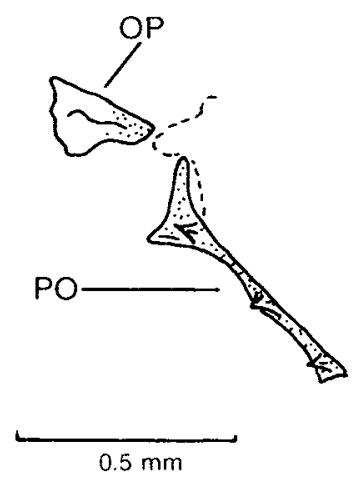

E

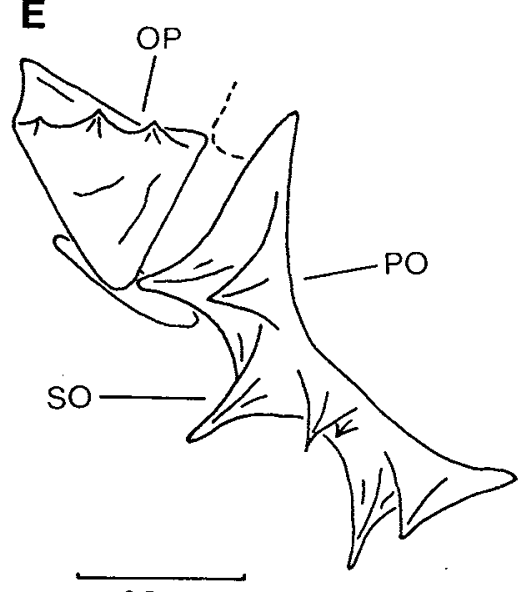

$\mathbf{F}$

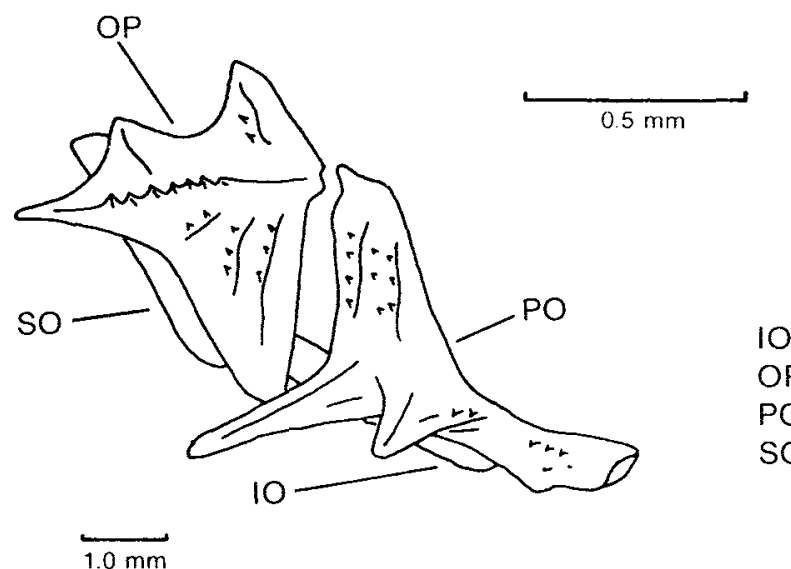

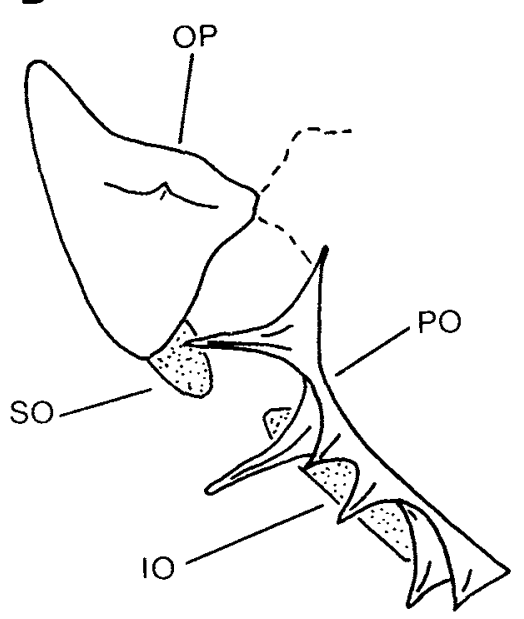

$0.5 \mathrm{~mm}$

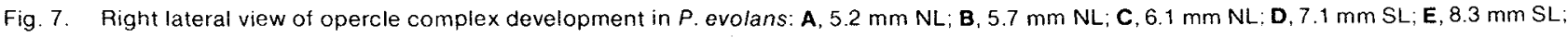
F, $31.0 \mathrm{~mm} \mathrm{SL}$.

The coracoid and scapula, which are present at hatching, arise from the same cartilage and remain fused together (Fig. 8A to 8F). Ossification of the coracoid commences at $11.5 \mathrm{~mm} \mathrm{SL}$ and is complete at 18.3 $\mathrm{mm} \mathrm{SL}$, but the scapula remained as cartilage in all specimens examined.

The radials are present as a broad cartilaginous plate at $3.1 \mathrm{~mm} \mathrm{NL}$ (Fig. 8A). Ossification of individual radials begins at $7.1 \mathrm{~mm}$ (Fig. 8D), and all four are present at $11.5 \mathrm{~mm}$ SL.

Attachment of the cleithrum to the occipital region of the skull is accomplished by the supracleithrum and posttemporal. The supracleithrum arises first as a slender cartilage at $5.8 \mathrm{~mm} \mathrm{NL}$ (Fig. 8C) overlapping the cleithrum. The posttemporal is visible at $6.3 \mathrm{~mm} \mathrm{SL}$ and joins the supracleithrum to the skull at $7.1 \mathrm{~mm} \mathrm{SL}$ (Fig. 8D). The two spines on the posttemporal at this time become reduced as the larva grows. Ossification is complete in both structures by $7.0 \mathrm{~mm} \mathrm{SL}$.
Pectoral rays are first evident at $3.8 \mathrm{~mm} \mathrm{NL}$ (Fig. $8 \mathrm{~B})$, and the adult complement is present at $5.8 \mathrm{~mm} \mathrm{NL}$ (Fig. 8C). Separation of the three feeler rays ventrally occurs at $11.5 \mathrm{~mm} \mathrm{SL}$, and the adult characteristic of about 13 bifurcated rays and three feeler rays is evident at $31.0 \mathrm{~mm} \mathrm{SL}$ (Fig. 8F).

\section{Pelvic fins (Fig. 9, Appendix Table F)}

The basipterygia are visible at $5.8 \mathrm{~mm} \mathrm{NL}$ as two separate oblong cartilaginous structures (Fig. 9A) which are located between the ventral tips of the cleithra. They expand anteriorly and posteriorly and their anterior tips are joined at $8.3 \mathrm{~mm} \mathrm{SL} \mathrm{(Fig.} \mathrm{9D).} \mathrm{Ossifica-}$ tion begins at $10.1 \mathrm{~mm} \mathrm{SL}$ and is complete in the 31.0 $\mathrm{mm}$ SL specimen (Fig. 9E). Two pelvic rays and the pelvic spine are present at $6.5 \mathrm{~mm} \mathrm{SL} \mathrm{(Fig.} \mathrm{9B)} \mathrm{and} \mathrm{the}$ full complement of one spine and five rays is attained at $7.5 \mathrm{~mm} \mathrm{SL}$ (Fig. 9C). The rays are segmented and bifurcated at $31.0 \mathrm{~mm} \mathrm{SL}$ (Fig. 9E). 
A

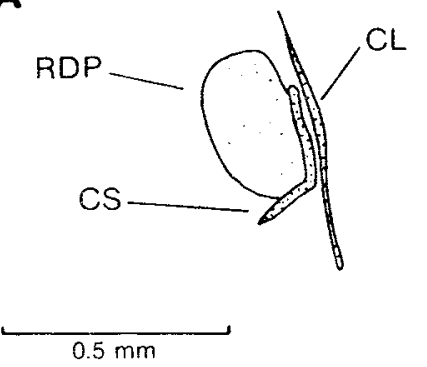

B

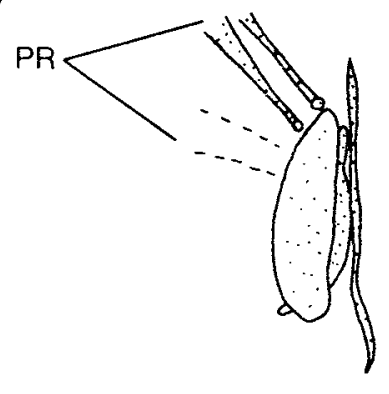

$0.5 \mathrm{~mm}$

D

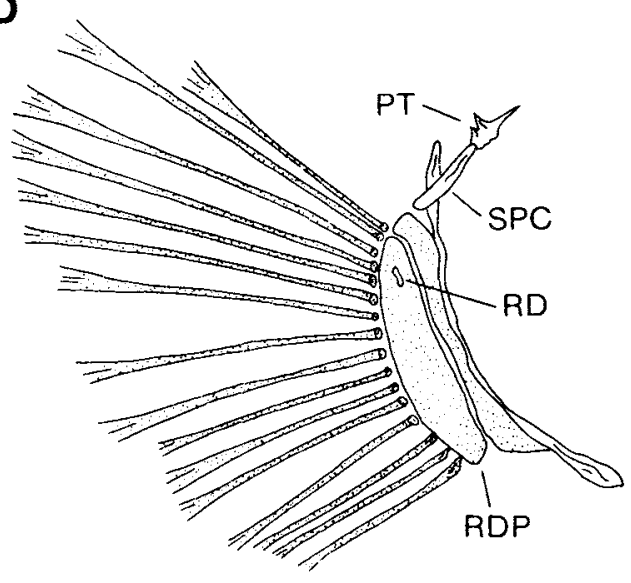

$0.5 \mathrm{~mm}$

$\mathbf{F}$

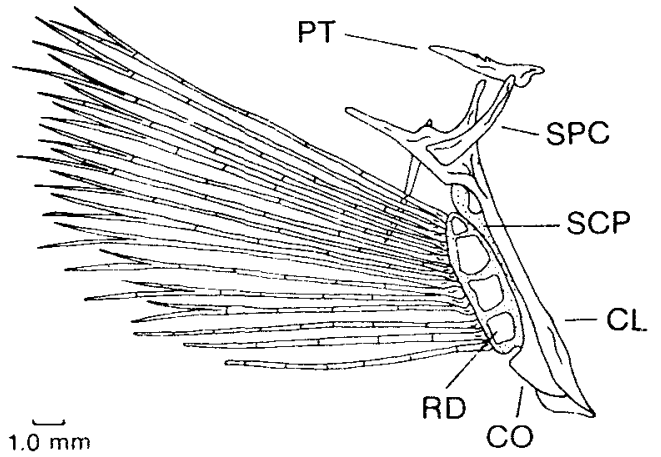

$\mathrm{CL}$
$\mathrm{CO}$
$\mathrm{CS}$
$\mathrm{DPC}$
$\mathrm{PR}$

C

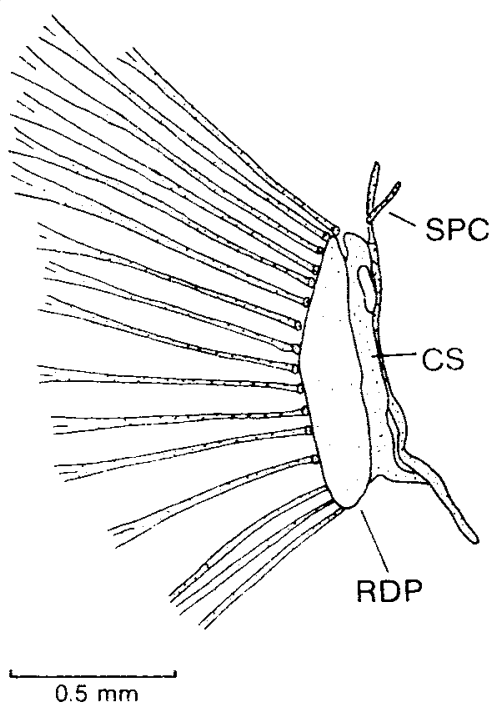

E

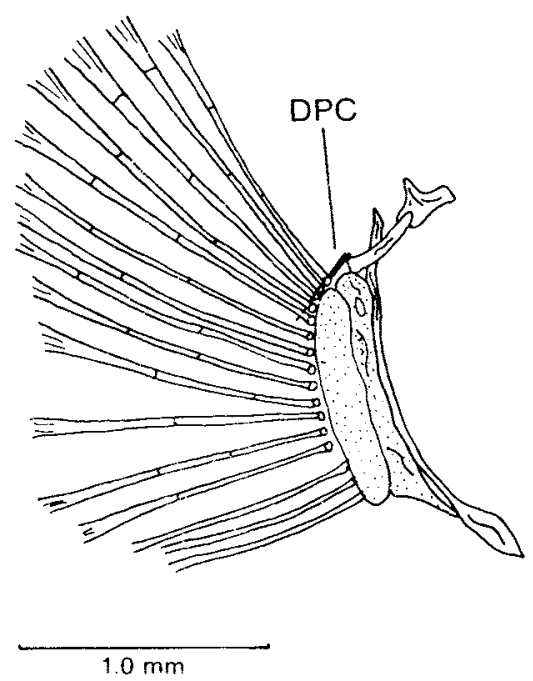

PT posttemporal

$\mathrm{RD}$ radial

RDP radial plate

SCP scapula

SPC supracleithrum

Fig. 8. Right lateral view of pectoral girdle development in P. evolans: A, $3.1 \mathrm{~mm} \mathrm{NL}$ : B, $3.8 \mathrm{~mm} \mathrm{NL} ;$ C, $5.8 \mathrm{~mm} \mathrm{NL}$. D. $71 \mathrm{~mm} \mathrm{SL}$ : E. $8.3 \mathrm{~mm} \mathrm{SL}$; F. $31.0 \mathrm{~mm} \mathrm{SL}$

\section{Caudal complex (Fig. 10, Appendix Table G)}

The caudal complex consists of five hypurals, three epurals, two neural spines, two haemal spines, urostyle and parhypural. The first caudal fin supports (hypurals 1 and 2) appear at $5.0 \mathrm{~mm} \mathrm{NL}$, and four hypurals and one haemal spine are present ventrally at
$5.7 \mathrm{~mm} \mathrm{NL}$ (Fig. 10A). The neural spines and one epural are present on the dorsal side of the notochord at 6.3 $\mathrm{mm} \mathrm{NL}$ (Fig. 10B). All epurals and the neural and haemal spines are present at $7.1 \mathrm{~mm} \mathrm{SL}$ (Fig. 10C). The fifth hypural is visible at $7.4 \mathrm{~mm} \mathrm{SL}$, and fusion of the hypurals into a broad plate begins with hypurals 3 and 4 at $8.3 \mathrm{~mm} \mathrm{SL} \mathrm{(Fig.} \mathrm{10D).} \mathrm{The} \mathrm{parhypural} \mathrm{and} \mathrm{urostyle}$ 
A

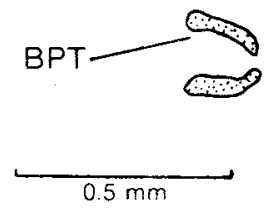

B

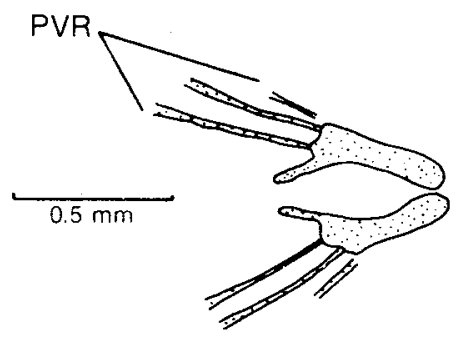

C

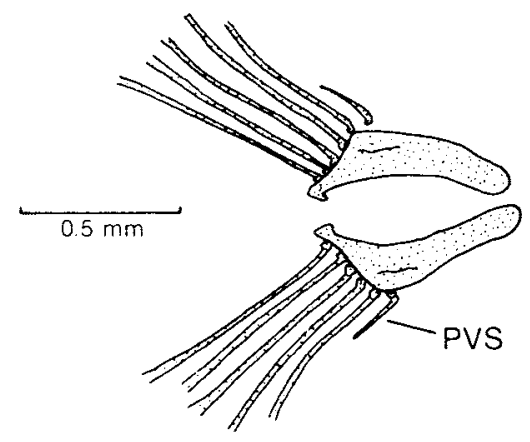

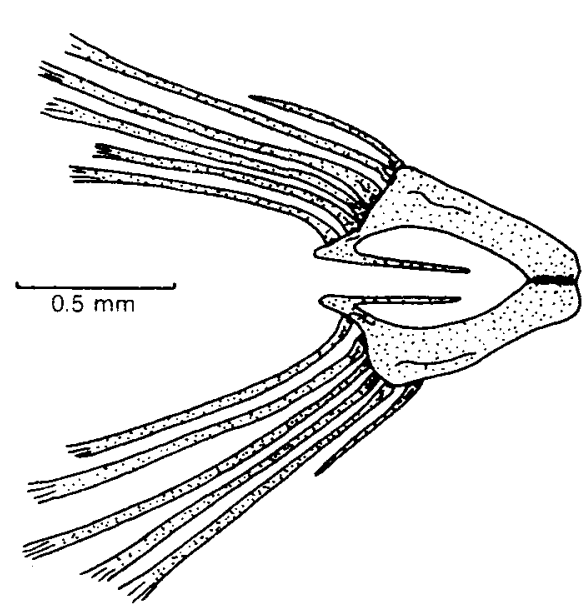

E

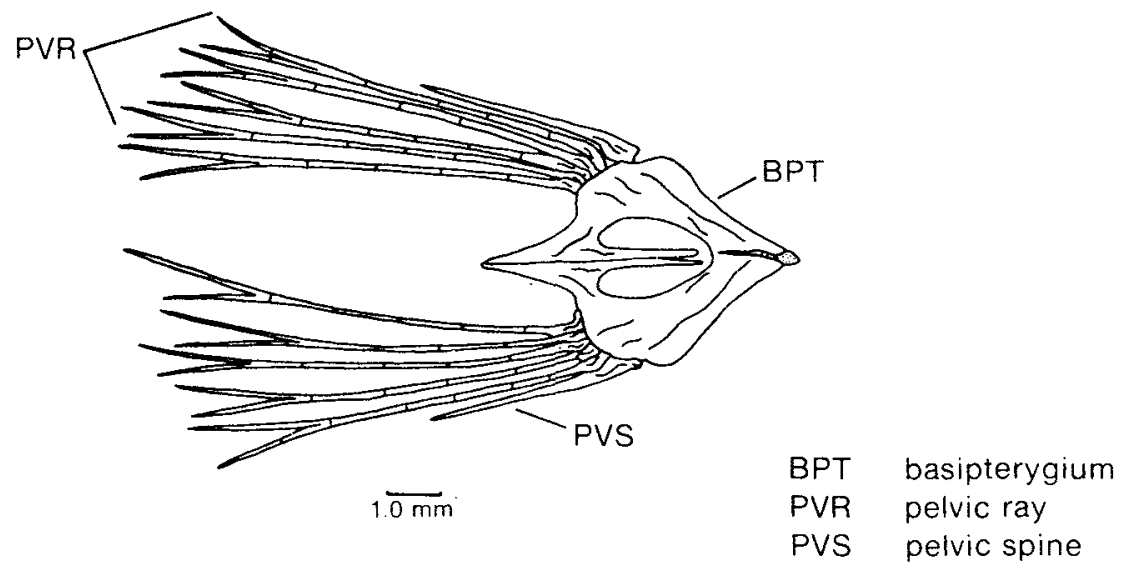

Fig. 9. Ventral view of pelvic girdle development in P. evolans: A, $5.8 \mathrm{~mm} \mathrm{NL} ; \mathbf{B}, 6.5 \mathrm{~mm} \mathrm{SL;} \mathrm{C.} 7.5 \mathrm{~mm} \mathrm{SL;} \mathrm{D,} 8.3 \mathrm{~mm} \mathrm{SL}$ : E, $31.0 \mathrm{~mm} \mathrm{SL}$.
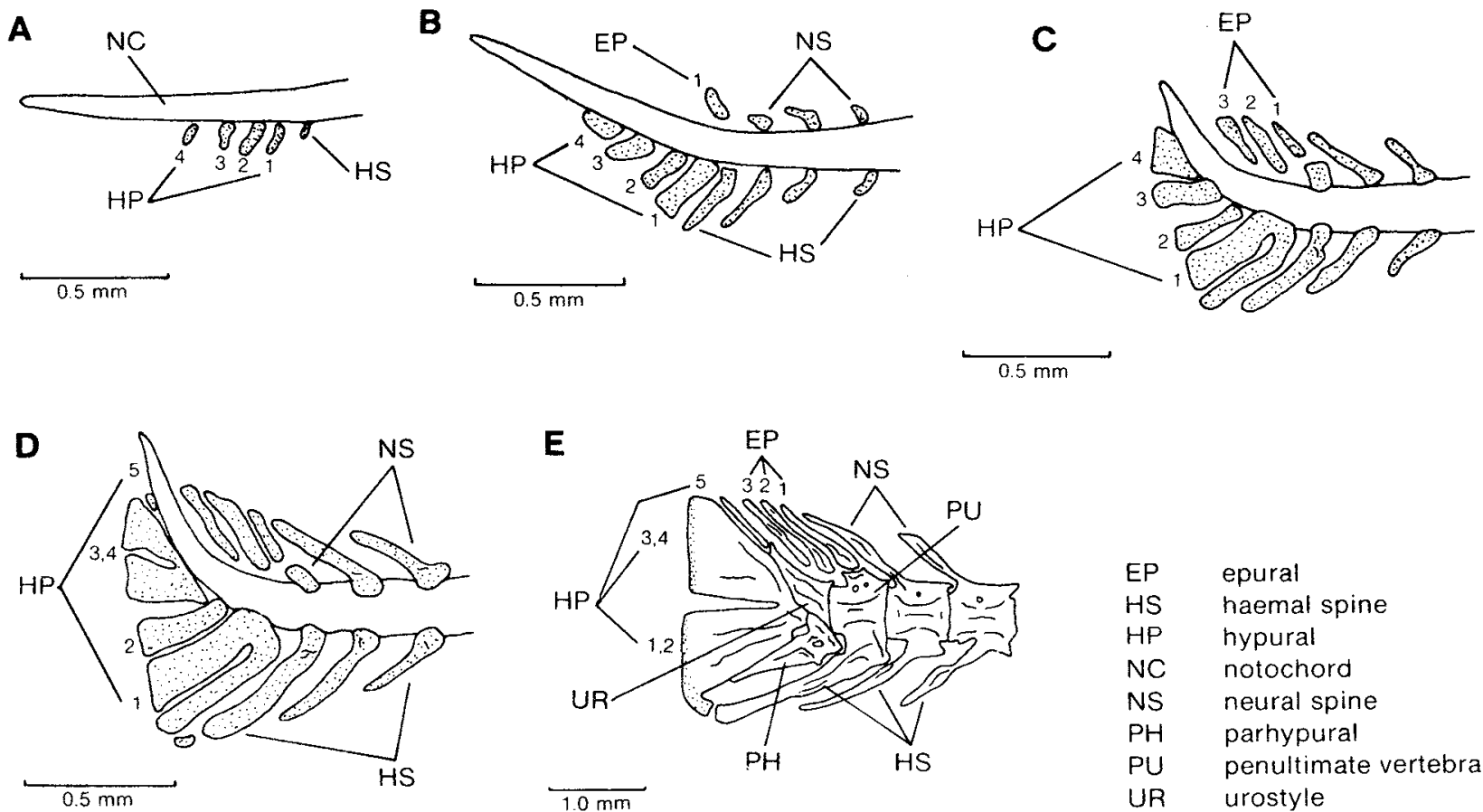

EP
$H S$
$H P$
$N C$
$N S$
$P H$
$P U$
UR

epural

haemal spine

hypural

notochord neural spine parhypural penultimate vertebrae urostyle

Fig. 10. Right lateral view of caudal complex development in P. evolans: A, $5.7 \mathrm{~mm} \mathrm{NL;} \mathrm{B,} 6.3 \mathrm{~mm} \mathrm{NL} ;$ C, $7.1 \mathrm{~mm} \mathrm{SL;} \mathrm{D,} 8.3 \mathrm{~mm} \mathrm{SL;} \mathrm{E,} 31.0$ $\mathrm{mm} \mathrm{SL}$. 
are present at $11.5 \mathrm{~mm} \mathrm{SL}$. Ossification of the caudal complex begins at $8.5 \mathrm{~mm} \mathrm{SL}$ in the hypural plates and is complete by $31.0 \mathrm{~mm} \mathrm{SL}$ (Fig. 10E).

\section{Backbone (Fig. 11, Appendix Table G)}

The vertebral column in the adult consists of 25 centra, 25 neural spines, 17-19 haemal spines, and 10-11 pleural ribs. The neural and haemal spines are first visible at 5.0 and $5.7 \mathrm{~mm} \mathrm{NL}$ respectively, there being three neural spines and 10 haemal spines in the $5.7 \mathrm{~mm} \mathrm{NL}$ specimen (Fig. 11A). Development of these structures proceeds posteriorly and the adult number is present at $6.1 \mathrm{~mm} \mathrm{NL}$ (Fig. 11B). Ossification of the neural and haemal spines begins in the anteriormost spines at $7.0 \mathrm{~mm} \mathrm{SL}$, proceeds posteriorly, and is complete at $31.0 \mathrm{~mm} \mathrm{SL}$ (Fig. 11E). Centra development is first noted at $5.7 \mathrm{~mm} \mathrm{NL}$. Pleural development begins at $8.3 \mathrm{~mm} \mathrm{SL} \mathrm{(Fig.} \mathrm{11D),} \mathrm{the} \mathrm{adult} \mathrm{complement} \mathrm{is} \mathrm{attained}$ at $11.5 \mathrm{~mm} \mathrm{SL}$, and ossification is complete at $17.1 \mathrm{~mm}$ $\mathrm{SL}$. Configuration of the adult backbone is represented in the $31.0 \mathrm{~mm}$ SL specimen (Fig. 11E).

\section{Caudal and median fins (Fig. 11, Appendix Table G)}

The caudal fin rays are first visible at $5.8 \mathrm{~mm} \mathrm{NL}$ and seven are present at $6.1 \mathrm{~mm} \mathrm{NL}$ (Fig. 11B). The number of principal rays increases to 10 at $6.6 \mathrm{~mm} \mathrm{SL}$ (Fig. $11 \mathrm{C}$ ) and to 13 at $7.5 \mathrm{~mm} \mathrm{SL}$.

The first dorsal fin in the adult consists of 10 spines which are supported by nine pterygiophores, with the anterior-most pterygiophore supporting two spines. Pterygiophores consist of proximal and distal sections, the proximals being the first to form at $5.8 \mathrm{~mm} \mathrm{NL}$. Three proximals are present as cartilage dorsoanteriorly over the neural spines at $6.1 \mathrm{~mm}$ NL (Fig. $11 \mathrm{~B})$. One dorsal spine is visible over the third pterygiophore and all proximal pterygiophores are present at $6.6 \mathrm{~mm} \mathrm{SL}$ (Fig. 11C). Seven dorsal spines are visible at $7.1 \mathrm{~mm} \mathrm{SL}$ and the adult number (10) is present at 7.8 $\mathrm{mm}$ SL. Articulation with the pterygiophores occurs throughout development of the spines and is complete by $8.3 \mathrm{~mm} \mathrm{SL}$ (Fig. 11D). At this size, the ventral tips of the pterygiophores extend between the neural spines, with a single pterygiophore in each interneural space except the third space which contains two. Ossification of the first dorsal spines and their supporting structures begins at $7.8 \mathrm{~mm} \mathrm{SL}$ and only the tips of the pterygiophores remain as cartilage at $31.0 \mathrm{~mm} \mathrm{SL} \mathrm{(Fig.}$ 11E).

The second dorsal fin in the adult is comprised of 12-13 rays which are supported by an equal number of pterygiophores. Four proximal pterygiophores are present at $6.2 \mathrm{~mm} \mathrm{NL}$ and the adult number at $6.6 \mathrm{~mm}$ $\mathrm{SL}$ (Fig. 11C). The formation of the distal parts of the pterygiophores coincides with the development of the second dorsal rays which begins at $6.5 \mathrm{~mm} \mathrm{SL}$. Seven rays are present at $6.6 \mathrm{~mm} \mathrm{SL} \mathrm{(Fig.} \mathrm{11C)} \mathrm{and} \mathrm{the} \mathrm{adult}$ complement at $7.7 \mathrm{~mm} \mathrm{SL}$. Articulation of the distal and proximal pterygiophores with the dorsal rays begins at $7.0 \mathrm{~mm}$ SL. The tips of the proximal pterygiophores extend ventrally between the neural spines at $8.3 \mathrm{~mm}$ SL (Fig. 11D), with a single pterygiophore in each interneural space except the 11th (or 12th) space which contains two. Ossification of the second dorsal rays and their supporting structures begins at $7.1 \mathrm{~mm} \mathrm{SL}$, and only the tips of the pterygiophores remain as cartilage at $31.0 \mathrm{~mm} \mathrm{SL} \mathrm{(Fig.} \mathrm{11E).}$

The anal fin in the adult consists of 11 rays which are supported by 10 pterygiophores. The two anteriormost rays are supported by a single pterygiophore. Four anterior proximal pterygiophores are present at $5.8 \mathrm{~mm} \mathrm{NL}$, six are visible at $6.1 \mathrm{~mm} \mathrm{NL}$ (Fig. 11B), and the full complement is attained by $7.0 \mathrm{~mm} \mathrm{SL}$. The anal rays and distal pterygiophores appear fused together at $6.4 \mathrm{~mm} \mathrm{SL}$. Seven rays are evident at $6.6 \mathrm{~mm} \mathrm{SL}$ (Fig. 11C) and development proceeds both anteriorly and posteriorly. The adult complement (11) is attained by $7.0 \mathrm{~mm}$ SL. Each interhaemal space is occupied by a single pterygiophore. Ossification of the anal fin begins at $7.1 \mathrm{~mm} \mathrm{SL}$, and only the tips of the pterygiophores remain cartilaginous at $31.0 \mathrm{~mm} \mathrm{SL}$ (Fig. 11E).

\section{Comparison of $P$. evolans and $P$. carolinus}

Attempts to separate the eggs and larvae of $P$. evolans and $P$. carolinus in earlier studies have generally been unsuccessful. Perlmutter (1939) and Wheatland (1956) used the patterns of oil globules to distinguish between eggs of the two species, the globules in $P$. evolans being clumped in the vicinity of one pole. This character was found to be unreliable by Richards (1959) and also in the present study when observations on $P$. evolans eggs were compared with those of Yuschak and Lund (1984), because the oil globules migrate to various locations during development in both species. Likewise, no difference in the numbers of oil globules was found between the two species.

Differences in the diameter of eggs from the two species have been reported. Marshall (1946) and Kuntz and Radcliffe (1917) reported egg diameter in P. carolinus to range from 1.00 to $1.15 \mathrm{~mm}$, but Yuschak and Lund (1984) found that the diameter of fertilized eggs ranged from 0.86 to $0.97 \mathrm{~mm}$ in the same species. In the present study, the diameter of eggs from $P$. evolans ranged from 1.00 to $1.25 \mathrm{~mm}$.

Morphological and pigmentation differences between the two species during egg development are few. Pigment is first visible in $P$. carolinus when the embryo extends about one-third around the yolk, but it 
A

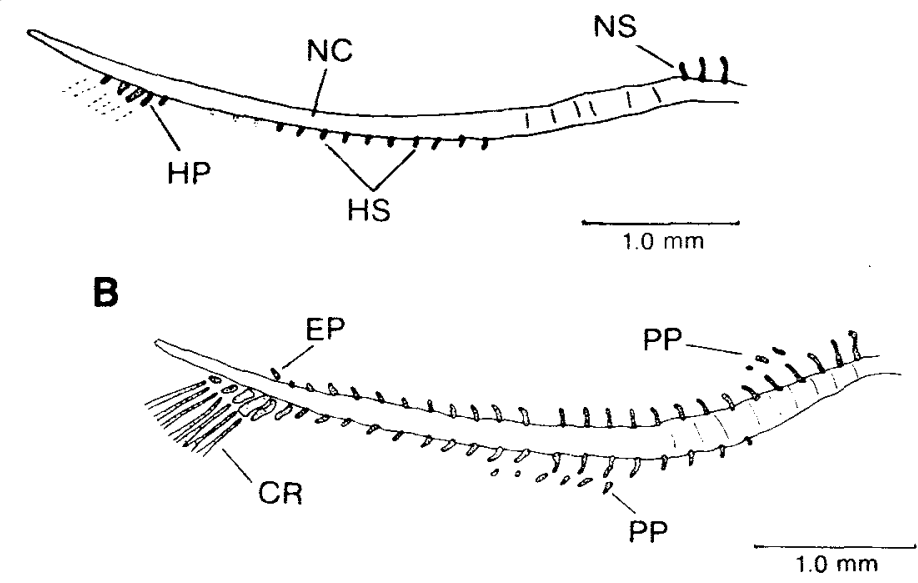

$\begin{array}{ll}\text { AR } & \text { anal ray } \\ \text { CN } & \text { centrum } \\ \text { CR } & \text { caudal ray } \\ \text { DP } & \text { distal pterygiophore } \\ \text { DR } & \text { dorsal ray } \\ \text { DS } & \text { dorsal spine } \\ \text { EP } & \text { epural } \\ \text { HP } & \text { hypural } \\ \text { NC } & \text { notochord } \\ \text { NS } & \text { neural spine } \\ \text { PCR } & \text { principal caudal ray } \\ \text { PL } & \text { pleural } \\ \text { PP } & \text { proximal pterygiophore } \\ \text { SCR } & \text { secondary caudal ray }\end{array}$

C

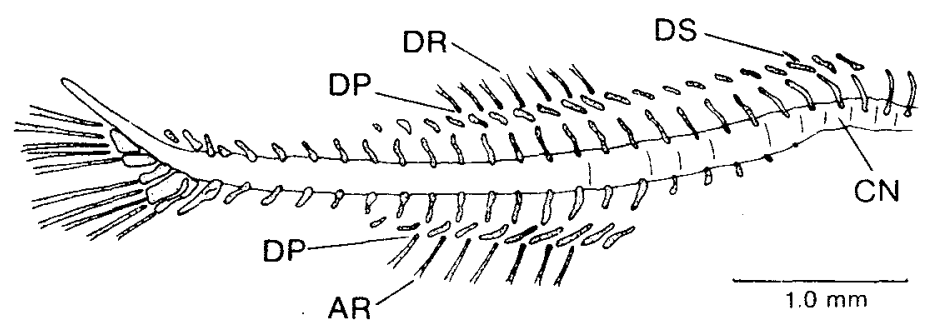

D
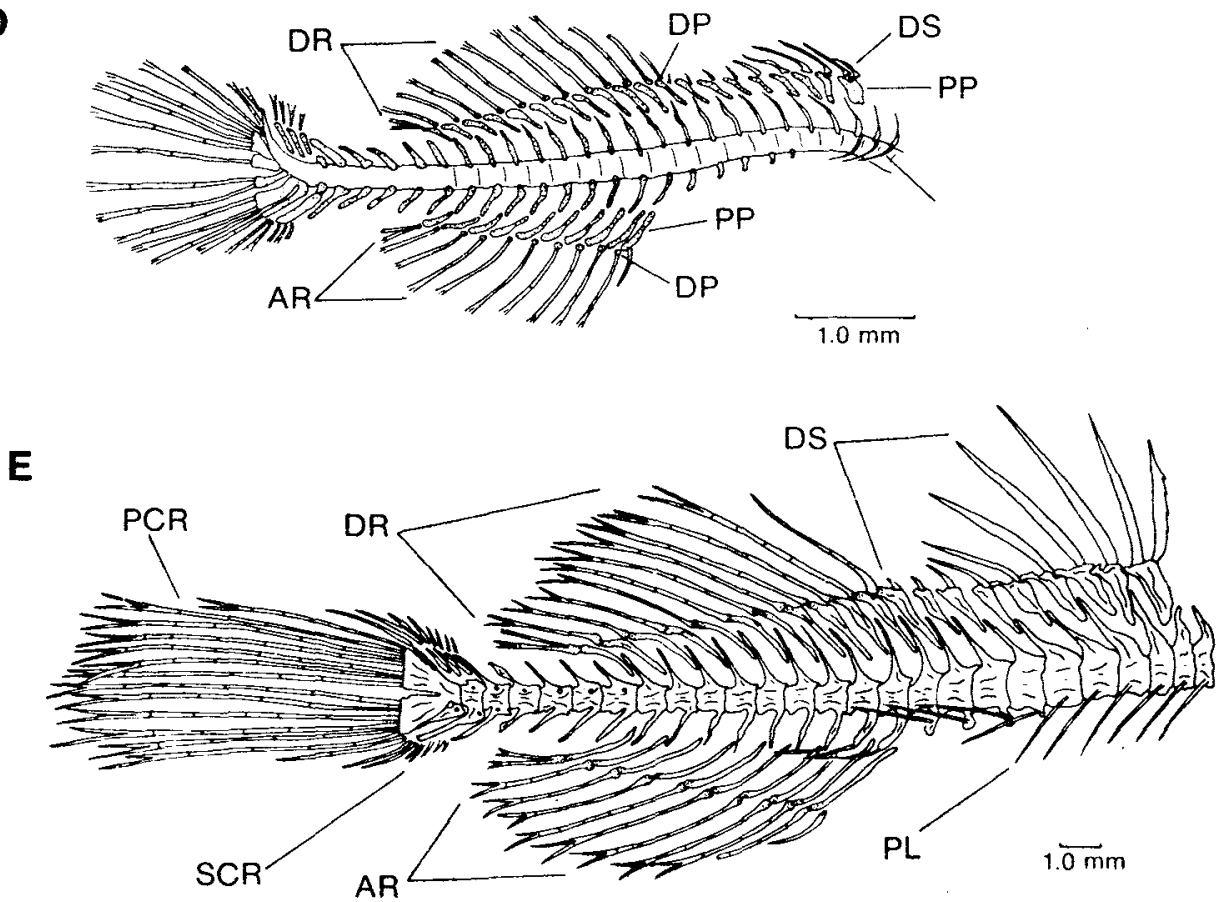

Fig. 11. Right lateral view of backbone and median fin development in P. evolans: A, $5.7 \mathrm{~mm} \mathrm{NL;} \mathrm{B,} 6.1 \mathrm{~mm} \mathrm{NL;} \mathrm{C.} 6.6 \mathrm{~mm} \mathrm{SL;} \mathrm{D,} 8.3 \mathrm{~mm} \mathrm{SL}$; E. $31.0 \mathrm{~mm} \mathrm{SL}$. 
is not noticeable in $P$. evolans until the embryo extends halfway around the yolk. A dense cluster of melanophores is present posterior to the eye in $P$. carolinus at the stage when the embryo extends halfway around the yolk, but the cluster is absent in P. evolans. Development of myomeres is slightly accelerated in P. evolans, but the two species are indistinguishable just prior to hatching. The size range at hatching of $P$. evolans larvae $(2.7-2.9 \mathrm{~mm} \mathrm{NL})$ overlaps that of $P$. carolinus (2.8-3.1 $\mathrm{mm} \mathrm{NL})$.

Some differences in morphology are evident during larval development, but the absence of specimens of $P$. carolinus larger than $7.0 \mathrm{~mm} \mathrm{SL}$ did not allow comparison with the larger $P$. evolans larvae in this paper. Yuschak and Lund (1984) reported that teeth were present in the upper and lower jaws of $P$. carolinus larvae as small as 4.0 and $5.4 \mathrm{~mm} \mathrm{NL}$ respectively, whereas teeth first formed on the upper jaw at $6.5 \mathrm{~mm}$ $\mathrm{SL}$ and on the lower jaw at $5.7 \mathrm{~mm} \mathrm{NL}$ in $P$. evolans larvae.

Fin formation is complete in $P$. carolinus at $7.0 \mathrm{~mm}$ $\mathrm{SL}$ and in $P$. evolans at $7.8 \mathrm{~mm} \mathrm{SL}$, this being particularly evident in pelvic fin development. In $P$. carolinus, the pelvic fin is first visible at $5.4 \mathrm{~mm} \mathrm{NL}$ and attains the adult complement of spines and rays at $6.3 \mathrm{~mm} \mathrm{SL}$. In $P$. evolans, this fin does not appear until $6.2 \mathrm{~mm} \mathrm{SL}$ and is complete at $7.5 \mathrm{~mm} \mathrm{SL}$. All other fins except the pectorals develop slightly later in $P$. evolans than in $P$. carolinus. The number of anal fin rays differed by one in $94 \%$ of all fish examined, there being 12 in $P$, carolinus and 11 in $P$. evolans.

In comparing the larvae of $P$. evolans in this paper with those of $P$. carolinus (Yuschak and Lund, 1984), the most noticeable difference was in the development of head spines. Although these spines develop earlier in $P$. carolinus, their sizes are much greater in $P$. evolans. The nuchal spine, which was misidentified as the parietal by Yuschak and Lund (1984), is the first spine visible at $4.0 \mathrm{~mm} \mathrm{NL}$ in $P$. carolinus and at $5.8 \mathrm{~mm} \mathrm{NL}$ in $P$. evolans. During development (Fig. 12), the nuchal spine in $P$. carolinus attains moderate size and expands to two spines at $7.0 \mathrm{~mm} \mathrm{SL}$. In contrast, this spine in $P$ evolans develops from a single low spine at $5.8 \mathrm{~mm} \mathrm{NL}$ to an elongate ridge with numerous spines at $8.3 \mathrm{~mm} \mathrm{SL}$. The postocular spine is first present at 6.0 $\mathrm{mm} \mathrm{NL}$ in $P$. carolinus (Fig. 13A) and at $6.6 \mathrm{~mm} \mathrm{SL} \mathrm{in} P$. evolans. At $7.0 \mathrm{~mm} \mathrm{SL}$, this spine is unchanged in $P$. carolinus (Fig. 13B) but has formed a ridge in $P$. evolans (Fig. 13D). The opercular and preopercular spines are similar in time of development, but the number of spines differs between the two species. $P$. carolinus has two and five preopercular spines at $6.0 \mathrm{~mm} \mathrm{NL}$ and $7.0 \mathrm{~mm}$ SL respectively, whereas $P$. evolans has four and six spines at $6.2 \mathrm{~mm} \mathrm{NL}$ and $7.0 \mathrm{~mm}$ SL respeclively. At $7.0 \mathrm{~mm} \mathrm{SL}$, two posttemporal spines are pres-

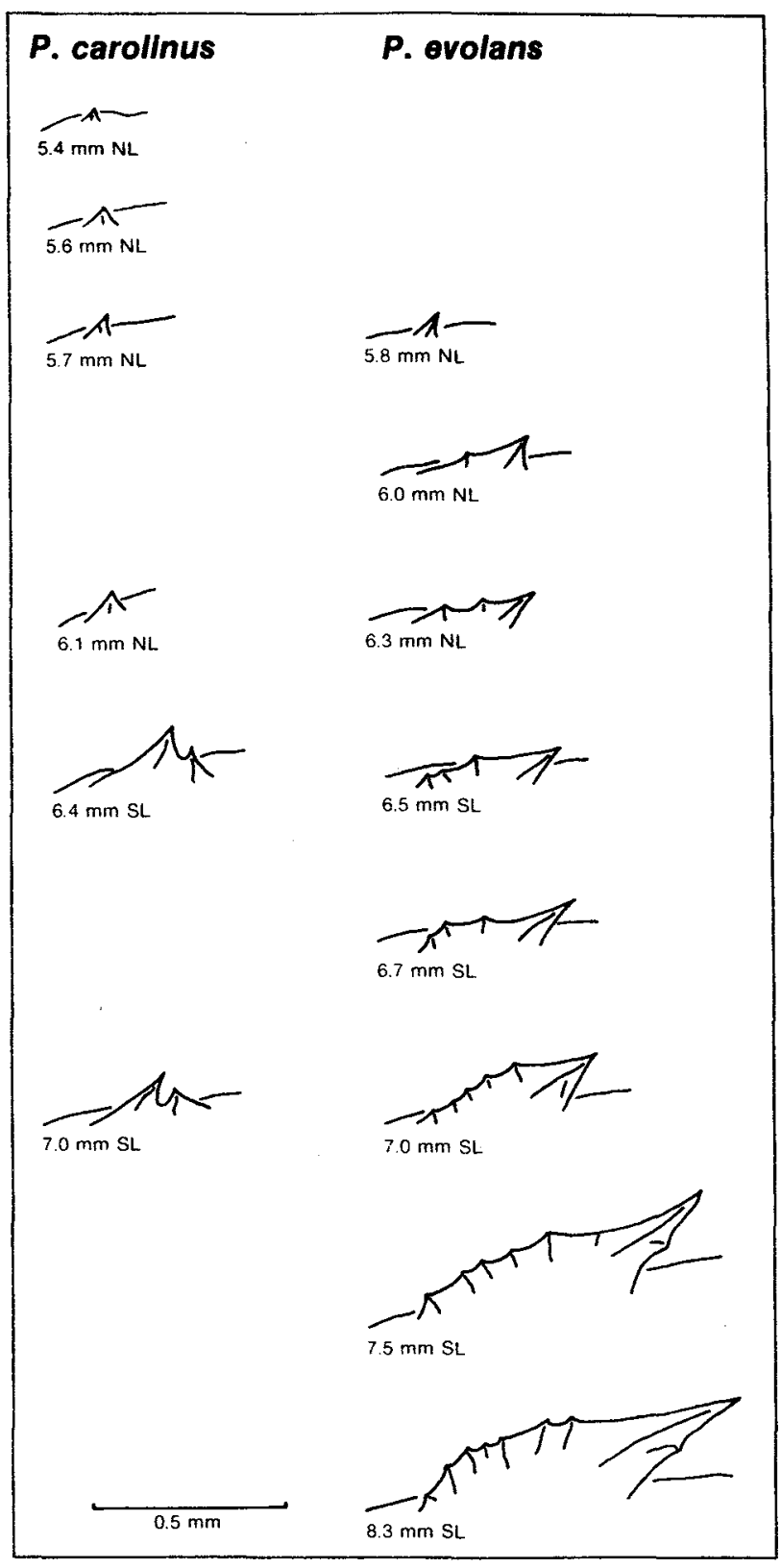

Fig. 12. Comparison of nuchal spine development in $P$ carolinus and P. evolans.

ent in P. carolinus but only one in P. evolans. In the size ranges of larvae compared (Fig. 13), the suborbital spine was found only in $P$. carolinus and the parietal and nasal spines only in $P$. evolans. The development of the sphenotic spine was similar in both species.

No difference in the presence or absence and the shape of cartilage and bones was observed between the two species. The dorsal postcleithrum, which is present in $P$. evolans (Fig. 8E), is also present in $P$. carolinus, but it was not mentioned by Yuschak and 


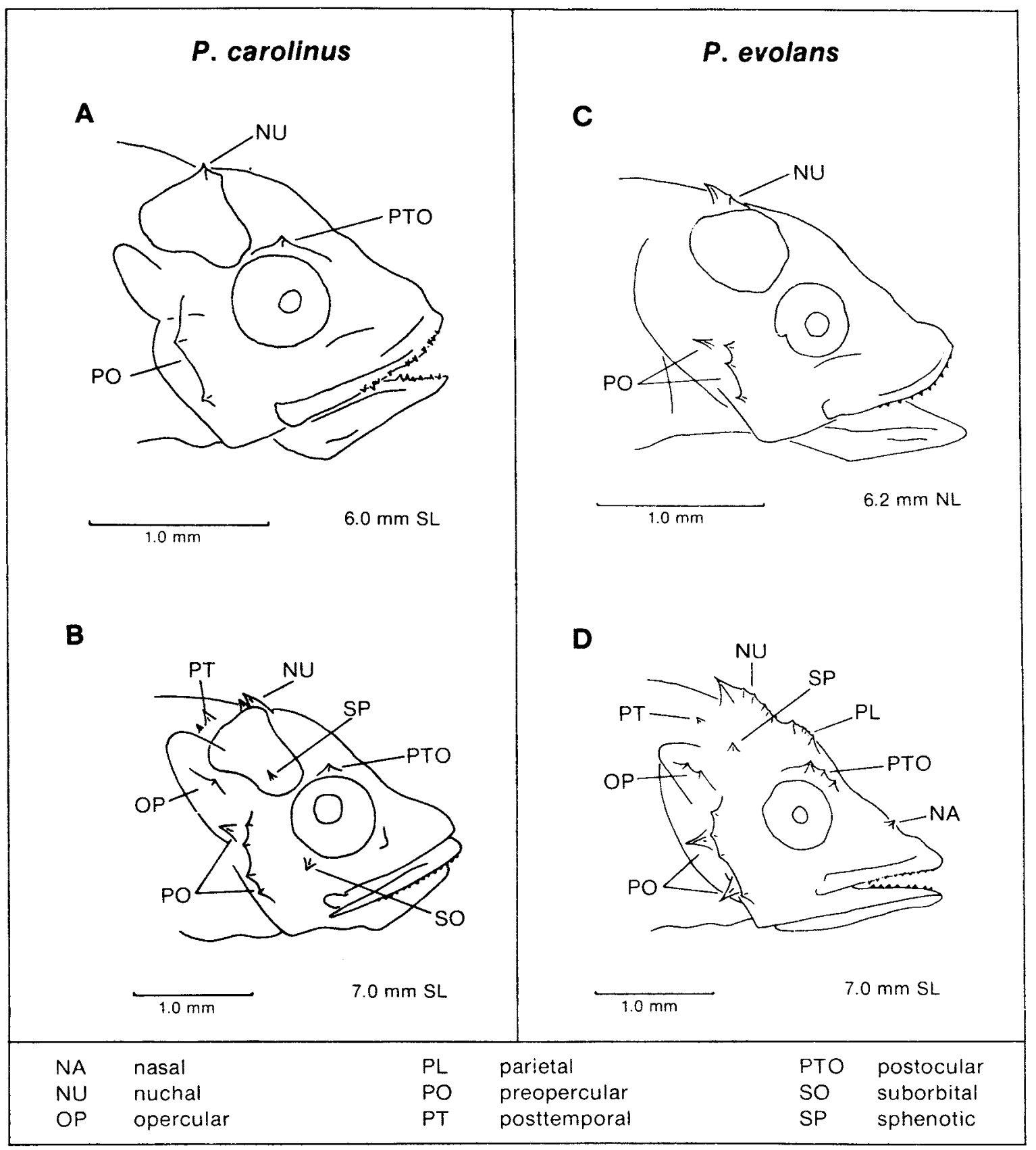

Fig. 13. Right lateral view of head spines in P. carolinus and $P$. evolans.

Lund (1984) due to the lack of specimens larger than $7.0 \mathrm{~mm} \mathrm{SL}$.

The major differences in osteological development of $P$. evolans and $P$. carolinus are limited to earlier appearance and accelerated development of certain structures in $P$. carolinus. Branchiostegal rays are present in $P$. carolinus at $4.4 \mathrm{~mm} \mathrm{NL}$ but are not visible in $P$. evolans until $5.0 \mathrm{~mm} \mathrm{NL}$. At $6.3 \mathrm{~mm} \mathrm{SL}$, the caudal complex of $P$. carolinus contains three epurals whereas that of $P$. evolans has only one. Ossification is slightly accelerated in $P$. carolinus.

\section{Acknowledgements}

My thanks go to Jennifer Alling, Greg Brewer and John Fowler for help in collecting and maintaining the adults and larvae, and especially to Sarah W. Richards for critical review of the manuscript.

\section{References}

BAGENAL, T. B. 1967. A short review of fish fecundity. In The biological basis of freshwater fish production (p. 89-111), S. D. Gerking (ed.), Blackwelt Scientific Publications, Oxford, England, 378 p. 
BAGENAL, T. B., and E. BRAUM. 1968. Eggs and early life history. In Methods for assessment of fish production in freshwaters ( $p .159-$ 181), W. E. Ricker (ed.), Blackwell Scientific Publications, Oxford England, $326 \mathrm{p}$.

BIGELOW, H. B., and W. C. SCHROEDER. 1953. Fishes of the Gulf of Maine. Fish. Bull. U.S., 53: 557 p

FAHAY, M. P. 1983. Guide to the early stages of marine fishes occurring in the western North Atlantic Ocean, Cape Hatteras to the southern Scotian Shelf. J. Northw. Atl. Fish. Sci., 4: 423 p.

GINSBURG, I. 1950. Review of the western Atlantic Triglidae (Fishes). Tex. J. Sci., 4: 489-527.

GOSLINE, W. A. 1961. The perciform caudal skeleton, Copeia, 1961: 265-269.

HOUDE, E. D., and T. POTTHOFF. 1976. Egg and larval development of the sea bream, Archosargus rhomboidalis (Linnaeus) (Pisces, Sparidae). Bull. Mar. Sci., 26: 506-529.

KUNTZ, A., and L. RADCLIFFE. 1917. Notes on the embryology and larval development of twelve teleostean fishes. Bull. U.S. Bur. Fish., 35: 87-134

LEIM, A. H., and W. B. SCOTT. 1966. Fishes of the Atlantic coast of Canada. Bull. Fish. Res. Board Can., 155: $485 \mathrm{p}$

MANN, J. M. MS 1974. Some aspects of the biology of the searobins, Prionotus carolinus and Prionotus evolans. M.A. Thesis, Long Island University, Greenvale, N.Y., 35 p.

MARSHALL, N. 1946. Observations on the comparative ecology of the two searobins, Prionotus carolinus and Prionotus evolans striatus Copeia, 1946: 118-144.

MCEACHRAN, J. D., and J. DAVIS. 1970. Age and growth of the striped searobin. Trans. Amer. Fish. Soc., 99: 343-352.

MILLER. G. C. 1965. A new species of searobin (Triglidae). Quart. J. Fla. Acad. Sci., 28: 259-266.

1967. A new species of western Atlantic armored searobin Peristedion greyae (Pisces, Peristediidae). Bull. Mar. Sci., 17: 16-41.

NICHOLS, J. T., and C. M. BREEDER, 1927. The marine fishes of New York and southern New England. Zoologica, 9: 1-192.

PERLMUTTER, A. 1939. A biological survey of the salt waters of Long
Island, 1938. Part II, Sect. I. An ecological survey of young fish and eggs identified from tow-net collections. N.Y. Conserv. Dept. Saltwater Survey, 1938(15): 11-71

PETERS, K. M. 1981. Reproductive biology and development osteology of the Florida blenny, Chasmodes saburrae (Perciformes: Blenniidae). Northeast. Gulf Sci., 4(2): 79-98.

POTTHOFF, T. 1974. Osteological development and variation in young tunas, genus Thunnus (Pisces, Scombridae), from the Atlantic Ocean. Fish. Bull. U.S., 72: 563-588.

1975. Development and structure of the caudal complex, the vertebral column, and the pterygiophores in the blackfin tuna (Thunnus atlanticus). Bull. Mar. Sci, 25: 205-231

1984. Clearing and staining techniques. In Ontogeny and systematics of fishes (p. 35-37), H. G. Moser, W. J. Richards, D. M Cohen, M. P. Fahay, A. W. Kendall Jr., and S. L. Richardson (ed.), Amer. Soc. Ichthy. Herp., Spec. Publ. No. 1, $760 \mathrm{p}$

RICHARDS, S. W. 1959. Oceanography of Long Island Sound. Pelagic fish eggs and larvae. Bull. Bingham Oceanogr. Coll., 17: 95-124

RICHARDS, S. W., J.M. MANN, and J. WALKER. 1979. Comparison of spawning season, age, growth rate and food of the two sympatric species of searobins, Prionotus carolinus and Prionotus evolans from Long Island Sound. Estuaries, 2: 255-268.

ROBERTS-GOODWIN, S. C. 1981. Biological and fisheries data on striped searobin, Prionotus evolans (Linnaeus). NOAA/NMFS Northeast Fish. Cent. Tech. Ser. Rep., No. 25, 59 p.

SCHLOSSMAN, P. A., and M. E. CHITTENDEN. 1981. Reproduction, movements, and population dynamics of the sand trout, Cynoscion arenarius. Fish. Bull. U.S., 79: 649-669.

TEAGUE, G. W. 1951. The searobins of America: a review of the triglid fishes of the genus Prionotus. Comun. Zool. Mus. Montevideo, $111(61): 1-53$.

WHEATLAND, S. B. 1956. Oceanography of Long Island Sound, 1952 1954. VII. Pelagic fish eggs and larvae. Bull. Bingham Oceanogr. Coll., 15: 234-314

YUSCHAK, P., and W. A. LUND. 1984. Eggs, larvae and osteological development of the northern searobin, Prionotus carolinus (Pisces, Triglidae). J. Northw. Atl. Fish. Sci., 5: 1-15. 


\section{Appendix}

The seven tables in this section provide detailed information on the development of the various structures which are described and illustrated in the "Osteology" section of the text. Tabled data in bold type refer to specimens which were undergoing notochord flexion. The following definitions pertain to abbreviations in the table headings and to terminology within the tables.

\begin{tabular}{|c|c|c|c|c|c|}
\hline AN & angular & $\mathrm{GH}$ & glossohyal & PVR & pelvic ray \\
\hline AR & anal ray & $\mathrm{HB}$ & hypobranchial & PVS & pelvic spine \\
\hline ART & articular & HS & haemal spine & $\mathrm{Q}$ & quadrate \\
\hline $\mathrm{BB}$ & $\begin{array}{l}\text { basibranchial } \\
\text { basihya! }\end{array}$ & HYM & hyomandibular & RD & radial \\
\hline $\mathrm{BPT}$ & basipterygium & IH & interhyal & RDP & radial plate \\
\hline $\mathrm{BR}$ & branchiostegal ray & 10 & interopercle & SCP & scapula \\
\hline CB & ceratobranchial & LP & lower pharyngeal & so & subopercle \\
\hline $\begin{array}{l}\mathrm{CH} \\
\mathrm{CL}\end{array}$ & $\begin{array}{l}\text { ceratohyal } \\
\text { cleithrum }\end{array}$ & MK & Meckel's cartilage & SYM & $\begin{array}{l}\text { supracleithrum } \\
\text { symplectic }\end{array}$ \\
\hline $\mathrm{CO}$ & coracoid & MT & metapterygoid & UH & uronyal \\
\hline $\mathrm{CS}$ & coracoid-scapula & $M X$ & maxilla & UP & $\begin{array}{l}\text { uronyal } \\
\text { upper pharyngeal }\end{array}$ \\
\hline DEN & dentary & NS & neural spine & UR & urostyle \\
\hline DDP & dorsal distal pterygiophore & OP & opercle & VDP & ventral distal pterygiophore \\
\hline DPP & dorsal proximal pterygiophore & PA & palatine & VPP & ventral proximal pterygiophore \\
\hline DR & dorsal ray & PCR & principal caudal ray & & \\
\hline DS & dorsal spine & $\mathrm{PH}$ & parhypural & & \\
\hline EB & epibranchial & $\mathrm{PL}$ & pleural & - & absent \\
\hline $\mathrm{ECH}$ & epiceratohyal & PM & premaxilla & + & present as cartilage \\
\hline $\mathrm{EH}$ & epihyal & $\mathrm{PO}$ & preopercle & 0 & present and ossifying \\
\hline ENT & entopterygoid & $\mathrm{PQ}$ & palato-quadrate & * & present and fully ossified \\
\hline EP & epural & PR & pectoral ray & $(T)$ & teeth present \\
\hline ET & ectopterygoid & PT & posttemporal & ( ) & digits indicate numbers present \\
\hline
\end{tabular}

TABLE A. Development of the jaw suspensorium in P. evolans. (Abbreviations and terminology are defined at the beginning of the Appendix.)

\begin{tabular}{|c|c|c|c|c|c|c|c|c|c|c|c|c|c|c|}
\hline $\operatorname{Size}(\mathrm{mm})$ & HYM & $Q$ & $\mathrm{MK}$ & $M X$ & PM & DEN & ART & $P Q$ & SYM & AN & $\mathrm{PA}$ & ENT & MT & ET \\
\hline $3.1-4.0$ & + & + & + & + & - & - & - & - & - & - & - & - & - & - \\
\hline $5.0-5.5$ & + & - & + & $\mathrm{O}$ & 0 & 0 & + & - & - & + & - & - & - & - \\
\hline $5.7-6.2$ & + & - & - & 0 & $O(T)$ & o & + & - & - & + & - & - & - & - \\
\hline $6.3-6.4$ & + & - & - & 0 & $O(T)$ & 0 & 0 & - & - & + & - & - & - & - \\
\hline $6.5-6.9$ & + & - & - & 0 & $O(T)$ & $O(T)$ & 0 & - & - & + & - & - & - & - \\
\hline $7.0-7.1$ & + & - & - & 0 & $O(T)$ & $\star(T)$ & 0 & - & - & + & - & - & - & - \\
\hline $7.4-7.5$ & o & - & - & $\star$ & $\star(T)$ & $\star(T)$ & 0 & - & - & + & - & - & - & - \\
\hline $7.7-9.8$ & 0 & - & - & $\star$ & $\star(T)$ & $\star(T)$ & 0 & - & - & 0 & - & - & - & -- \\
\hline $10.1-10.5$ & $\mathrm{o}$ & + & - & $\star$ & $\star(T)$ & $\star(T)$ & 0 & - & $?$ & 0 & - & - & - & - \\
\hline 10.9 & 0 & + & - & $\star$ & $\star(T)$ & $\star(T)$ & 0 & $?$ & $?$ & 0 & - & - & $\rightarrow$ & - \\
\hline 11.5 & $\mathrm{O}$ & 0 & - & $\star$ & $\star(T)$ & $\star(T)$ & 0 & 0 & 0 & 0 & $\mathrm{o}$ & - & - & - \\
\hline $12.4-14.9$ & 0 & 0 & - & $\star$ & $\star(T)$ & $\star(\mathrm{T})$ & 0 & 0 & $\star$ & 0 & $\mathrm{o}$ & - & - & - \\
\hline 15.2 & $\star$ & $\star$ & - & $\star$ & $\star(T)$ & $\star(T)$ & 0 & o & * & 0 & 0 & - & 0 & - \\
\hline 17.1 & $\star$ & $\star$ & - & $\star$ & $\star(T)$ & $\star(T)$ & 0 & $\star$ & * & $\star$ & $\star$ & 0 & 0 & $\star$ \\
\hline 18.3 & * & $\star$ & - & $\star$ & $\star(T)$ & $\star(T)$ & 0 & $\star$ & 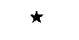 & $\star$ & $\star$ & $\star$ & 0 & * \\
\hline 31.0 & $\star$ & $\star$ & - & $\star$ & $\star(T)$ & $\star(T)$ & $\star$ & $\star$ & 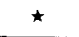 & * & $\star$ & $\star$ & $\star$ & 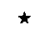 \\
\hline
\end{tabular}


TABLE B. Development of the branchial arch in P. evolans. (Abbreviations and terminology are defined at the beginning of the Appendix.)

\begin{tabular}{lcccccc}
\hline \hline Size $(\mathrm{mm})$ & $\mathrm{CB}$ & $\mathrm{BB}$ & $\mathrm{HB}$ & $\mathrm{EB}$ & UP & LP \\
\hline $3.1-3.3$ & $+(4)$ & $+(3)$ & $+(3)$ & - & - & - \\
$3.8-4.0$ & $+(4)$ & $+(3)$ & $+(3)$ & - & + & - \\
$5.0-5.2$ & $+(4)$ & $+(3)$ & $+(3)$ & $+(4)$ & + & + \\
$5.5-6.1$ & $+(4)$ & $+(3)$ & $+(4)$ & $+(4)$ & $+(T)$ & $+(T)$ \\
$6.2-7.4$ & $+(4)$ & $+(4)$ & $+(4)$ & $+(4)$ & $+(T)$ & $+(T)$ \\
$7.5-8.5$ & $O(4)$ & $+(4)$ & $+(4)$ & $+(4)$ & $+(T)$ & $+(T)$ \\
$9.0-15.2$ & $O(4)$ & $O(4)$ & $O(4)$ & $O(4)$ & $O(T)$ & $O(T)$ \\
$17.1-18.3$ & $O(4)$ & $\star(4)$ & $O(4)$ & $O(4)$ & $\star(T)$ & $O(T)$ \\
31.0 & $\star(4)$ & $\star(4)$ & $O(4)$ & $\star(4)$ & $\star(T)$ & $\star(T)$ \\
\hline
\end{tabular}

TABLE C. Development of the hyoid arch in $P$, evolans. (Abbreviations and terminology are defined at the beginning of the Appendix.)

\begin{tabular}{ccccccccc}
\hline \hline Size $(\mathrm{mm})$ & $\mathrm{ECH}$ & $\mathrm{IH}$ & $\mathrm{BH}$ & $\mathrm{UH}$ & $\mathrm{GH}$ & $\mathrm{EH}$ & $\mathrm{CH}$ & $\mathrm{BR}$ \\
\hline $3.1-3.3$ & + & + & - & - & - & - & - & - \\
$3.8-4.0$ & + & + & + & - & - & - & - & - \\
$5.0-5.5$ & + & + & + & - & - & - & - & 3 \\
5.7 & + & + & + & - & - & - & - & 4 \\
$5.8-6.0$ & + & + & + & - & - & - & - & 6 \\
6.1 & + & + & + & - & - & - & - & 7 \\
$6.2-6.3$ & + & + & + & + & - & - & - & 7 \\
$6.4-6.9$ & + & + & + & + & + & - & - & 7 \\
$7.0-7.7$ & 0 & + & + & 0 & + & - & - & 7 \\
$7.8-14.5$ & $\mathrm{O}$ & + & + & $\star$ & + & - & - & 7 \\
14.9 & 0 & $\star$ & + & $\star$ & + & - & - & 7 \\
15.2 & - & $\star$ & + & $\star$ & + & 0 & 0 & 7 \\
17.1 & - & 0 & + & $\star$ & + & 0 & 0 & 7 \\
18.3 & - & 0 & 0 & $\star$ & + & 0 & $\star$ & 7 \\
31.0 & - & 0 & 0 & $\star$ & 0 & $\star$ & $\star$ & 7 \\
\hline
\end{tabular}

TABLE D. Development of the opercle complex in $P$. evolans. (Abbreviations and terminology are defined at the beginning of the Appendix.)

\begin{tabular}{ccccc}
\hline \hline Size $(\mathrm{mm})$ & OP & PO & 10 & SO \\
\hline $3.1-5.0$ & - & - & - & - \\
$5.2-5.8$ & + & + & - & - \\
$6.0-6.2$ & 0 & + & - & - \\
6.3 & 0 & 0 & - & - \\
6.4 & 0 & 0 & + & - \\
$6.5-6.7$ & $\star$ & 0 & + & + \\
$6.9-7.7$ & $\star$ & $\star$ & + & + \\
$7.8-7.9$ & $\star$ & $\star$ & 0 & 0 \\
$8.0-8.2$ & $\star$ & $\star$ & 0 & $\star$ \\
$8.3-31.0$ & $\star$ & $\star$ & $\star$ & $\star$ \\
\hline
\end{tabular}

TABLE E. Development of the pectoral girdle in P. evolans. (Abbreviations and terminology are defined at the beginning of the Appendix.)

\begin{tabular}{cccccccccc}
\hline \hline Size $(\mathrm{mm})$ & $\mathrm{CL}$ & $\mathrm{CS}$ & $\mathrm{RDP}$ & $\mathrm{SPC}$ & $\mathrm{PT}$ & $\mathrm{RD}$ & $\mathrm{CO}$ & SCP & PR \\
\hline $3.1-3.3$ & + & + & + & - & - & - & - & - & - \\
3.8 & + & + & + & - & - & - & - & - & 2 \\
4.0 & + & + & + & - & - & - & - & - & 3 \\
5.0 & + & + & + & - & - & - & - & - & 11 \\
5.2 & + & + & + & - & - & - & - & - & 12 \\
5.5 & + & + & + & - & - & - & - & - & 13 \\
5.7 & + & + & + & - & - & - & - & - & 14 \\
5.8 & + & + & + & + & - & - & - & - & 16 \\
$6.0-6.2$ & 0 & + & + & 0 & - & - & - & - & 16 \\
$6.3-6.4$ & 0 & + & + & 0 & + & - & - & - & 16 \\
$6.5-6.9$ & $\star$ & + & + & 0 & + & - & - & - & 16 \\
7.0 & $\star$ & + & + & $\star$ & $\star$ & - & - & - & 16 \\
$7.1-9.0$ & $\star$ & + & + & $\star$ & $\star$ & 1 & - & - & 16 \\
$9.2-9.8$ & $\star$ & + & + & $\star$ & $\star$ & 2 & - & - & 16 \\
$10.1-10.9$ & $\star$ & + & + & $\star$ & $\star$ & 3 & - & - & 16 \\
$11.5-17.1$ & $\star$ & 0 & + & $\star$ & $\star$ & 4 & 0 & + & $13+3^{*}$ \\
$18.3-31.0$ & $\star$ & $\star$ & + & $\star$ & $\star$ & 4 & $\star$ & + & $13+3$ \\
\hline Separation of feeler rays. & & & & & &
\end{tabular}

TABLE F. Development of the pelvic girdle in P. evolans. (Abbreviations and terminology are defined at the beginning of the Appendix.)

\begin{tabular}{cccc}
\hline \hline Size $(\mathrm{mm})$ & BPT & PVS & PVR \\
\hline $3.1-5.7$ & - & - & - \\
$5.8-6.4$ & + & - & - \\
6.5 & + & 1 & 2 \\
6.7 & + & 1 & 3 \\
$6.9-7.4$ & + & 1 & 4 \\
$7.5-9.8$ & + & 1 & 5 \\
$10.1-18.3$ & 0 & 1 & 5 \\
31.0 & $\star$ & 1 & 5 \\
\hline
\end{tabular}


TABLE G. Development of the backbone, caudal complex and median fins in P. evolans. (Abbreviations and terminology are defined at the beginning of the Appendix.)

\begin{tabular}{|c|c|c|c|c|c|c|c|c|c|c|c|c|c|c|c|c|c|c|c|}
\hline Size $(\mathrm{mm})$ & \multicolumn{5}{|c|}{ Hypural } & $E P$ & $\mathrm{PH}$ & UR & NS & HS & DPP & DDP & VPP & VDP & PCR & $A R$ & DR & DS & $\mathrm{PL}$ \\
\hline $3.1-4.0$ & - & - & - & - & - & - & - & - & - & - & - & - & - & - & - & - & - & - & - \\
\hline 5.5 & + & + & + & - & - & - & - & - & $+(1)$ & - & - & - & - & - & - & - & - & - & - \\
\hline 5.7 & + & + & + & - & - & - & - & - & $+(3)$ & $+(10)$ & - & - & - & - & - & - & - & - & - \\
\hline 5.8 & + & + & + & + & - & $+(1)$ & - & - & $+(3)$ & $+(19)$ & $+(1)$ & - & $+(4)$ & - & 5 & - & - & - & - \\
\hline 6.2 & + & + & + & + & - & $+(1)$ & - & - & $+(25)$ & $+(19)$ & $+(9)$ & - & $+(6)$ & - & 7 & - & - & - & - \\
\hline 6.3 & + & + & + & + & - & $+(1)$ & - & - & $+(25)$ & $+(19)$ & $+(13)$ & - & $+(7)$ & - & 9 & - & - & - & - \\
\hline 6.4 & + & + & + & + & - & $+(1)$ & - & - & $+(25)$ & $+(19)$ & $+(16)$ & - & $+(7)$ & $+(7)$ & 9 & 7 & - & - & - \\
\hline 6.5 & + & + & + & + & - & $+(3)$ & - & - & $+(25)$ & $+(19)$ & $+(20)$ & $+(7)$ & $+(9)$ & $+(7)$ & 9 & 7 & 7 & 1 & - \\
\hline 6.7 & + & + & + & + & - & $+(3)$ & - & - & $+(25)$ & $+(19)$ & $+(20)$ & $+(7)$ & $+(9)$ & $+(7)$ & 10 & 7 & 7 & 1 & - \\
\hline 6.9 & + & + & + & + & - & $+(3)$ & - & - & $+(25)$ & $+(19)$ & $+(20)$ & $+(7)$ & $+(9)$ & $+(8)$ & 10 & 9 & 9 & 4 & - \\
\hline 7.0 & + & + & + & + & + & $+(3)$ & - & - & $O(25)$ & $O(19)$ & $+(20)$ & $+(7)$ & $+(9)$ & $+(8)$ & 10 & 9 & 9 & 4 & - \\
\hline $7.8-8.1$ & + & + & + & + & + & $+(3)$ & - & - & $O(25)$ & $O(19)$ & $+(20)$ & $+(15)$ & $+(10)$ & $+(11)$ & 13 & 11 & 12 & 10 & - \\
\hline 8.2 & + & + & + & + & + & $+(3)$ & - & - & $O(25)$ & $O(19)$ & $+(20)$ & $+(16)$ & $+(10)$ & $+(11)$ & 13 & 11 & 12 & 10 & - \\
\hline 8.3 & + & + & + & + & + & $\neq(3)$ & - & - & $O(25)$ & $O(19)$ & $+(20)$ & $+(20)$ & $+(10)$ & $+(11)$ & 13 & 11 & 12 & 10 & $+(3)$ \\
\hline $8.5-9.8$ & O & 0 & 0 & 0 & + & $+(3)$ & - & - & $O(25)$ & $O(19)$ & $+(20)$ & $+(20)$ & $+(10)$ & $+(11)$ & 13 & 11 & 12 & 10 & $+(3)$ \\
\hline 10.1 & 0 & 0 & 0 & 0 & + & $+(3)$ & - & - & $O(25)$ & $O(19)$ & $+(20)$ & $+(20)$ & $+(10)$ & $+(11)$ & 13 & 11 & 12 & 10 & $+(4)$ \\
\hline 10.3 & 0 & 0 & 0 & 0 & + & $+(3)$ & - & - & $O(25)$ & $O(19)$ & $+(20)$ & $+(20)$ & $+(10)$ & $+(11)$ & 13 & 11 & 12 & 10 & $+(6)$ \\
\hline 10.5 & 0 & 0 & $\mathrm{O}$ & 0 & + & $\mathrm{O}(3)$ & - & - & $O(25)$ & $O(19)$ & $+(20)$ & $+(20)$ & $+(10)$ & $+(11)$ & 13 & 11 & 12 & 10 & $O(6)$ \\
\hline 10.9 & 0 & 0 & $O$ & 0 & + & $O(3)$ & - & - & $O(25)$ & $O(19)$ & $O(20)$ & $+(20)$ & $O(10)$ & $+(11)$ & 13 & 11 & 12 & 10 & $O(6)$ \\
\hline 11.5 & 0 & 0 & 0 & 0 & 0 & $\mathrm{O}(3)$ & 0 & 0 & $O(25)$ & $O(19)$ & $\star(20)$ & $+(20)$ & $O(10)$ & $+(11)$ & 13 & 11 & 12 & 10 & $O(7)$ \\
\hline 12.4 & 0 & 0 & 0 & 0 & $\mathrm{O}$ & $O(3)$ & 0 & 0 & $O(25)$ & $0(19)$ & $\star(20)$ & $O(20)$ & $O(10)$ & $O(11)$ & 13 & 11 & 12 & 10 & $O(10)$ \\
\hline $14.5-17.1$ & 0 & 0 & 0 & 0 & 0 & $O(3)$ & $\star$ & $\star$ & $O(25)$ & $O(19)$ & $\star(20)$ & $O(20)$ & $O(10)$ & $O(11)$ & 13 & 11 & 12 & 10 & $O(10)$ \\
\hline 18.3 & 0 & $\mathrm{O}$ & 0 & 0 & $\mathrm{O}$ & $O(3)$ & $\star$ & $\star$ & $O(25)$ & $O(19)$ & $\star(20)$ & $O(20)$ & $\star(10)$ & $O(11)$ & 13 & 11 & 12 & 10 & $\star(10)$ \\
\hline 31.0 & $\star$ & $\star$ & $\star$ & $\star$ & $\star$ & $\star(3)$ & $\star$ & $\star$ & $\star(25)$ & $\star(19)$ & $\star(20)$ & $O(20)$ & $\star(10)$ & $O(11)$ & 13 & 11 & 12 & 10 & $\star(10)$ \\
\hline
\end{tabular}


